\title{
Arrest functions of the MIF ligand/receptor axes in atherogenesis
}

\author{
Sabine Tillmann ${ }^{1}$, Jürgen Bernhagen ${ }^{1,2} *$ and Heidi Noels ${ }^{3 *}$ \\ 1 Institute of Biochemistry and Molecular Cell Biology, RWTH Aachen University, Aachen, Germany \\ ${ }^{2}$ August-Lenz-Stiftung, Institute for Cardiovascular Research, Ludwig-Maximilians-University Munich, Munich, Germany \\ ${ }^{3}$ Institute of Molecular Cardiovascular Research, RWTH Aachen University, Aachen, Germany
}

\section{Edited by:}

Klaus Ley, La Jolla Institute for Allergy and Immunology, USA

\section{Reviewed by:}

Alexander Zarbock, University of Muenster, Germany

Brian Petrich, University of California

San Diego, USA

\section{*Correspondence:}

Jürgen Bernhagen, Institute of Biochemistry and Molecular Cell Biology, RWTH Aachen University, Pauwelsstrasse 30, D-52074 Aachen, Germany.

e-mail: jbernhagen@ukaachen.de; Heidi Noels, Institute of Molecular Cardiovascular Research, RWTH Aachen University, Pauwelsstrasse 30, D-52074 Aachen, Germany. e-mail:hnoels@ukaachen.de
Macrophage migration inhibitory factor (MIF) has been defined as an important chemokinelike function (CLF) chemokine with an essential role in monocyte recruitment and arrest. Adhesion of monocytes to the vessel wall and their transendothelial migration are critical in atherogenesis and many other inflammatory diseases. Chemokines carefully control all steps of the monocyte recruitment process. Those chemokines specialized in controlling arrest are typically immobilized on the endothelial surface, mediating the arrest of rolling monocytes by chemokine receptor-triggered pathways. The chemokine receptor CXCR2 functions as an important arrest receptor on monocytes. An arrest function has been revealed for the bona fide CXCR2 ligands CXCL1 and CXCL8, but genetic studies also suggested that additional arrest chemokines are likely to be involved in atherogenic leukocyte recruitment. While CXCR2 is known to interact with numerous $\mathrm{CXC}$ chemokine ligands, the CLF chemokine MIF, which structurally does not belong to the CXC chemokine sub-family, was surprisingly identified as a non-cognate ligand of CXCR2, responsible for critical arrest functions during the atherogenic process. MIF was originally identified as macrophage migration inhibitory factor (this function being eponymous), but is now known as a potent inflammatory cytokine with CLFs including chemotaxis and leukocyte arrest. This review will cover the mechanisms underlying these functions, including MIF's effects on LFA1 integrin activity and signal transduction, and will discuss the structural similarities between MIF and the bona fide CXCR2 ligand CXCL8 while emphasizing the structural differences. As MIF also interacts with CXCR4, a chemokine receptor implicated in CXCL12-elicited lymphocyte arrest, the arrest potential of the MIF/CXCR4 axis will also be scrutinized as well as the recently identified role of pericyte MIF in attracting leukocytes exiting through venules as part of the pericyte "motility instruction program."

Keywords: chemokine, leukocyte recruitment, arrest, signal transduction, atherosclerosis, inflammation

\section{INTRODUCTION}

Leukocyte recruitment and arrest are central steps in inflammatory reactions and associated diseases, including atherosclerosis (Box 1). Identifying the main players mediating chemotaxis and arrest is therefore crucial. Boisvert et al. (1998) revealed an important role for the chemokine receptor CXCR2 in mediating monocyte recruitment into atherosclerotic lesions by showing a reduced lesion size and macrophage content in atherosclerosisprone $\mathrm{Ldll}^{-1-}$ mice transplanted with $\mathrm{Cxcr2}$-deficient bone marrow. Although mice do not express an ortholog of the CXCL8/IL8 ligand of human CXCR2, the Cxcr2 ligand Cxcl1 (also known as $\mathrm{KC} / \mathrm{Gro}-\alpha$ ) was detected in advanced lesions in mice (Boisvert et al., 1998) ${ }^{1}$. However, a subsequent study in 2006 showed that the reduction in lesion size in Cxcll-deficient $\mathrm{Ldlr}^{-1-}$ mice didn't

\footnotetext{
${ }^{1}$ Throughout the manuscript, the letter format of all gene and protein notations was chosen to conform with internationally agreed gene/protein nomenclature guidelines: all letters of human genes/proteins are in uppercase, whereas for mouse genes/proteins, only the first letter is in uppercase and the remaining letters are in lowercase. Gene names are in italics.
}

exceed half of what was observed in the bone marrow-specific Cxcr2 knock-out (Boisvert et al., 2006), suggesting the presence of other relevant $\mathrm{Cxcr} 2$ ligands with an important role in monocyte recruitment during atherogenesis. In fact, one such factor was uncovered a year later and was found to be the inflammatory cytokine macrophage migration inhibitory factor (MIF). MIF was originally discovered half a century ago as a T-cell-derived factor inhibiting the random migration of macrophages out of capillary tubes and thus was termed macrophage migration inhibitory factor. However, following its cloning and the biochemical characterization and preparation of MIF protein, MIF was later on redefined to be a pleiotropic inflammatory cytokine with critical roles in physiological immunity but also inflammatory diseases and cancer (Bernhagen et al., 1993; Calandra and Roger, 2003). Although the migration inhibitory activity of MIF was not studied and characterized much further, the eponymous name "MIF" was kept up over the years. It was thus largely unexpected, when MIF was identified as a ligand of CXCR2, exhibiting chemokinelike properties, and shown to be a crucial pro-atherogenic factor (Bernhagen et al., 2007). Intriguingly, MIF/CXCR2 interaction 


\section{Box 1 | The leukocyte adhesion cascade.}

Leukocyte arrest on inflamed endothelium can be divided into three main steps: rolling, adhesion, and transmigration. Leukocyte rolling is mediated by the binding of leukocyte-derived PSGL1 to the selectins P-selectin and E-selectin on inflamed endothelial cells (ECs). Next, chemokines triggering their respective G protein-coupled receptor (GPCR) on the leukocyte cell surface promote leukocyte integrin activation, resulting in leukocyte arrest. Finally, leukocytes transmigrate across the endothelium into the vessel wall, which can occur by paracellular (through endothelial junctions) or transcellular route (through the EC body). This three-step model has been refined over the last years, to include tethering (capture), rolling, slow rolling, arrest, adhesion strengthening, intraluminal crawling, and transmigration (Ley et al., 2007).

was found to trigger the recruitment and arrest of monocytes, whereas MIF-mediated T-cell recruitment could be traced to an interaction of MIF and yet another chemokine receptor. This was CXCR4, a CXC chemokine receptor thought to be much more specific regarding its ligand spectrum than CXCR2 (Bernhagen et al., 2007). Interestingly, MIF-mediated monocyte recruitment had previously been described in other inflammatory diseases, such as arthritis and glomerulonephritis (Lan et al., 1997; Morand et al., 2006), but was thought to represent an indirect event at the time. And although the third MIF receptor CD74 was already identified as a MIF-interacting membrane protein in 2003, a direct role of CD74 in MIF-mediated monocyte chemotaxis and arrest was not revealed until the discovery of CXCR2/CD74 complexes in 2007. Interestingly, it is now also clear that CD74 has a role in atherogenesis (Sun et al., 2010).

This review discusses MIF's role as a chemokine-like mediator, addressing its structure, receptor binding capacity and importance in leukocyte recruitment, particularly arrest, in the context of atherosclerosis.

\section{MIF AS AN IMPORTANT CHEMOKINE-LIKE FUNCTION - CHEMOKINE}

Chemokines are 8-12 kDa cytokines with chemotactic properties, playing a fundamental role in leukocyte trafficking (Bajetto et al., 2002; Weber et al., 2004; Charo and Ransohoff, 2006). Typically, a chemokine consists of a disordered N-terminus containing a characteristic cysteine motif, an $\mathrm{N}$-loop region, three antiparallel $\beta$-strands linked by turns designated 30s-, 40s-, and 50s-loop, and a C-terminal $\alpha$-helix, which together form the typical chemokine fold (Clark-Lewis et al., 1995). Chemokines share 20-50\% gene and amino acid homology, and are classified into four groups depending on the presence and spacing of their N-terminal cysteine residues. These groups comprise the $\mathrm{C}, \mathrm{CC}, \mathrm{CXC}$, and CXXXC chemokines, with the CXC and CC groups being most prominent (Murphy et al., 2000). The N-terminal cysteine motif stabilizes the chemokine structure by forming two disulfide bonds, one between the first cysteine with a cysteine in the 30s-loop, and the other one between the second cysteine and a cysteine in the 50sloop (Fernandez and Lolis, 2002). Chemokines exert their specific function by binding to rhodopsin-like $G$ protein-coupled receptors (GPCRs), which contain a seven-transmembrane domain and signal through heterotrimeric $\mathrm{G}$ proteins (Thelen and Didichenko, 1997; Murphy et al., 2000; Thelen, 2001; Bajetto et al., 2002; Charo and Ransohoff, 2006). The receptors are classified according to the chemokines they bind (Murphy et al., 2000). It has been suggested that for all chemokine sub-groups, the binding mechanism follows a so-called two-site-binding mechanism. First, there is an interaction between the $\mathrm{N}$-loop of the chemokine with the $\mathrm{N}$-terminus of the receptor (site I interaction). This results in a conformational change of the receptor and allows a second interaction between the N-terminus of the chemokine and the extracellular loops of the receptor (site II interaction) (Clark-Lewis et al., 1995; Rajagopalan and Rajarathnam, 2006).

In the last decade, there was a raising need to establish an additional chemokine category, to accomodate proteins that exhibit similar functions as the prototypical, "classical" chemokines, but that lack the typical chemokine structure. Characteristics of this group of "chemokine-like function (CLF) - chemokines" were defined as follows: (i) CLF chemokines are released during infection, inflammation, or cell stress by non-classical export or due to cell death; (ii) they do not usually share the typical chemokine fold and the N-terminal residues with the classical chemokines; (iii) they exhibit chemokine-like activities in particular promoting chemotaxis; and (iv) they typically interact with a GPCR, preferentially functioning as non-cognate ligand of a classical chemokine receptor (Degryse and de Virgilio, 2003; Yang et al., 2004; Oppenheim and Yang, 2005; Noels et al., 2009). Some representatives of this sub-group and their characteristic features are listed in Table 1.

MIF is a typical CLF chemokine, as missing cysteines in its $\mathrm{N}$-terminus do not allow for a classification of MIF into one of the four prototypical chemokine classes, although MIF shares several features with chemokines (Box 2). As such, MIF mediates the recruitment of monocytes, T-cells, neutrophils, endothelial progenitor cells, and tumor cells (Ren et al., 2003; Gregory et al., 2006; Bernhagen et al., 2007; Takahashi et al., 2009; Brandau et al., 2010; Dessein et al., 2010; Simons et al., 2011). Furthermore, MIF is immobilized on the endothelial cell (EC) surface (Schober et al., 2004; Bernhagen et al., 2007), where it induces leukocyte arrest (Schober et al., 2004; Amin et al., 2006). Interestingly, MIF was shown to directly mediate these chemokine-like functions by triggering the activation of leukocytic integrins (Box 3) through the CXC chemokine receptors CXCR2 and CXCR4 on monocytes/neutrophils and T-cells, respectively (Bernhagen et al., 2007; Zernecke et al., 2008; Kraemer et al., 2012), as discussed in more detail below.

In addition, MIF indirectly enhances leukocyte arrest by inducing the expression of adhesion molecules or other chemokines. This has been observed for both endogenous and exogenous MIF on ECs and leukocytes, either by MIF stimulation alone, or by MIF in combination with other pro-inflammatory stimuli. For example, Mif-deficient mice show a reduced adhesion of leukocytes to the endothelium of the cremaster microvasculature upon injection of inflammatory agents such as Tnf $\alpha$ and lipopolysaccharide (LPS), or chemokines such as $\mathrm{Cxcl} 1$ or $\mathrm{Ccl} 2$ 


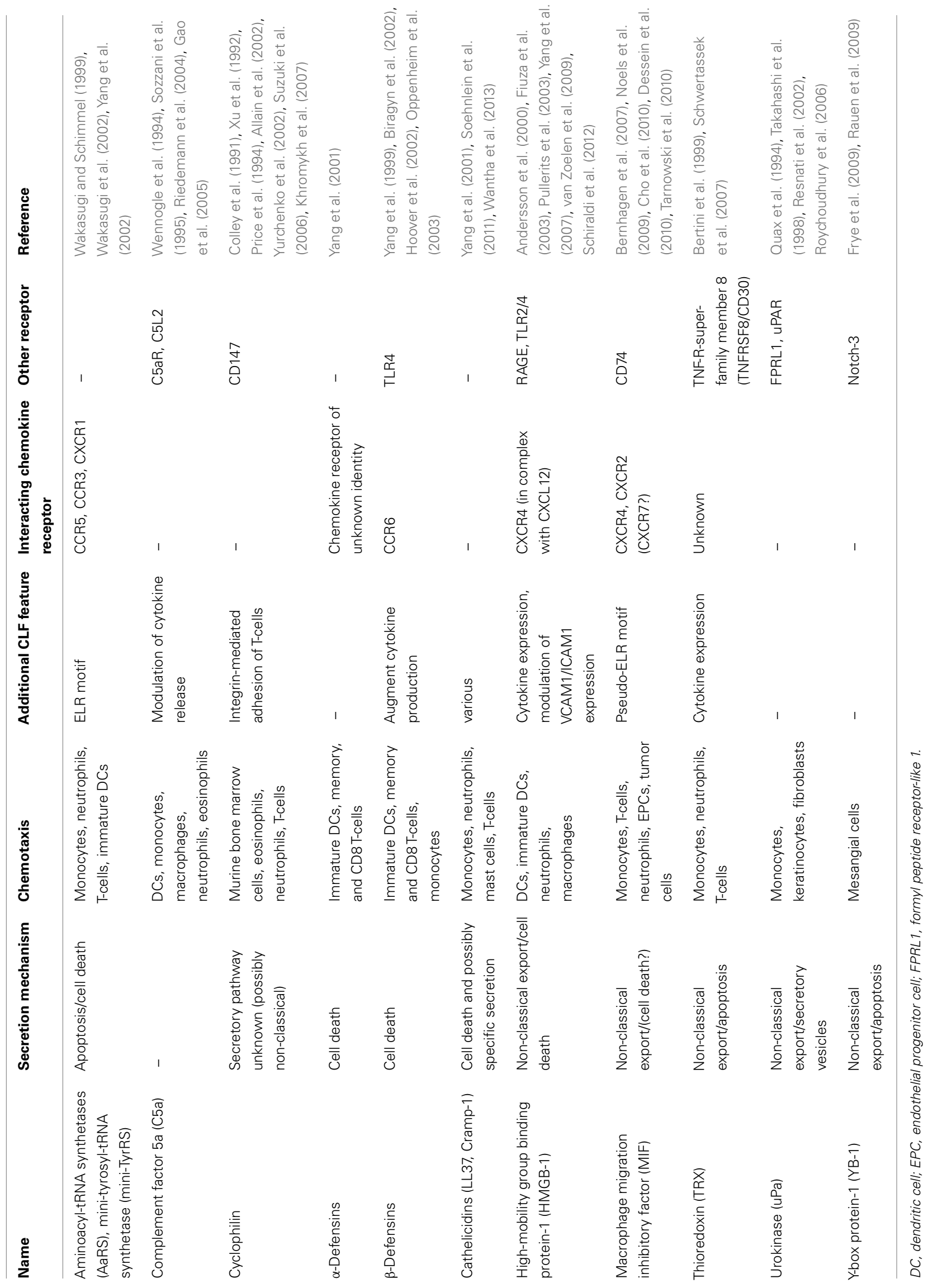




\section{Box 2 | Macrophage migration inhibitory factor (MIF).}

Macrophage migration inhibitory factor (MIF) is a pleiotropic inflammatory cytokine with chemokine-like functions, thus placing it into the CLF chemokine class. The sequence of MIF differs by only one residue from a protein mediator called glycosylation-inhibiting factor (GIF). The name "macrophage migration inhibitory factor" goes back to the initial discovery of MIF in 1966, when MIF-containing T-cell supernatants were found to inhibit the random migration of guinea pig macrophages out of capillary tubes (David, 1966). As a CLF chemokine, MIF acts as a chemoattractant for leukocytes, endothelial progenitor cells, and certain tumor cells, and mediates many pro-inflammatory processes through the induction of cytokines, chemokines, and adhesion molecules. Also, MIF counteracts the anti-inflammatory activity of glucocorticoids. MIF has been implicated in a variety of acute and chronic inflammatory diseases like sepsis, atherosclerosis, rheumatoid arthritis, inflammatory lung disease, or systemic lupus erythematosus. MIF also is a tumor promoter in most models (Calandra and Roger, 2003). MIF signals through its high affinity receptor CD74, a surface form of the MHC class II invariant chain li, and through the chemokine receptors CXCR2 and CXCR4. Apart from CLF functions, MIF exhibits evolutionarily conserved catalytic activities as an oxidoreductase and tautomerase activity. The physiological and pathophysiological relevance of these catalytic functions, which can readily be detected in vitro, is still unclear (Kraemer et al., 2012). The tautomerase activity of MIF is shared by D-dopachrome tautomerase (D-DT), a protein with 34\% amino acid homology to MIF in humans, and $27 \%$ in mice. D-DT also binds to CD74 and has a broad overlapping spectrum of functions and therefore was recently designated as MIF-2 (Merk et al., 2012). Unfortunately, MIF is frequently mixed up with another chemokine with a similar name, i.e., macrophage inflammatory protein-1 $\alpha$ (MIP-1 $\alpha$ or CCL3). This chemokine also acts in a pro-inflammatory manner and is produced and secreted by macrophages, but unlike MIF, MIP- $1 \alpha$ is classified into the CC chemokine class and is formally not related to MIF by structure.

\section{Box 3 | Integrins.}

Integrins are $\alpha \beta$ heterodimeric transmembrane proteins mediating the arrest of cells to the extracellular matrix (ECM) or other cells through interaction with ECM proteins (e.g., fibronectin, laminin, collagen, and vitronectin) or integrin ligands (e.g., VCAM1, ICAM1), respectively. Currently, $19 \alpha$ and $8 \beta$ subunits have been identified in vertebrates, which can be assembled into 24 different integrins. Well-studied are the $\beta_{1}$-integrin VLA4 $\left(\alpha_{4} \beta_{1}\right)$ and the $\beta_{2}$-integrins LFA1 $\left(\alpha_{L} \beta_{2}, C D 11 a / C D 18\right)$ and MAC1 $\left(\alpha_{M} \beta_{2}, C D 11 b / C D 18\right)$, which bind to VCAM1 and ICAM1, respectively (Zhang and Wang, 2012). The association strength between a specific integrin heterodimer and a ligand is called "integrin affinity." It is dependent on the composition and conformation of the integrin, the latter being modulated by intracellular signaling events triggered by, e.g., GPCR stimulation. For LFA1, at least 3 different conformations have been demonstrated. In its "closed," inactive state, the extracellular domain of LFA1 is bent towards the plasma membrane, with the ligand-binding headpiece situated close to the membrane, preventing ligand binding. An intermediate affinity of LFA1 has been linked to an "intermediate extended" state with a closed ligand-binding headpiece extending above the plasma membrane. The high affinity, "open" conformation of LFA1 is coupled to the "opening" of the ligand-binding headpiece through conformational rearrangements. This "open headpiece" of LFA1 has been shown to be necessary and sufficient for cell arrest under flow (Lefort and Ley, 2012).

Besides integrin affinity, cellular adhesion strength is affected by the integrin density, or valency, on the cell surface. This is regulated by integrin expression and clustering, and contributes to the joined, synergistic strength of all integrin-ligand interactions, called "integrin avidity" or "functional affinity." In addition to intracellular signaling cascades regulating integrin affinity (called "inside-out signaling"), ligand binding by integrins also mediates "outside-in signaling" affecting cellular processes, as for example gene expression, cell proliferation and survival.

(Gregory et al., 2004; Fan et al., 2011; Santos et al., 2011). For $\mathrm{TNF} \alpha$, this could be linked to a reduced basal and TNF $\alpha$-triggered expression of the integrin ligands VCAM1 and ICAM1, and of the cytokines IL6, CXCL8, and CCL2 in MIF-deficient ECs, possibly through a reduced TNF $\alpha$-induced $\mathrm{p} 38$ activation in the absence of MIF (Cheng et al., 2010). Similarly, the cremaster muscle microvasculature of Mif-deficient mice showed a diminished LPS-induced Vcam1 expression pattern (Gregory et al., 2009). Also, Cxcl1induced chemotaxis was significantly reduced in Mif-deficient neutrophils and was associated with a reduced mitogen-activated protein kinase (Mapk) activation (Santos et al., 2011). Similarly, Ccl2-triggered monocyte chemotaxis was severely decreased in the absence of endogenous Mif. This was associated with a reduced Rho GTPase and Mapk activation, and a reduced expression of the $\alpha 4$ integrin and of the Mapk-regulating protein Mkp1 in Mif-deficient macrophages (Fan et al., 2011). Likewise, exogenous MIF has been linked to an enhanced expression of chemokines and adhesion molecules. For example, injection of mice with recombinant MIF increased monocyte adhesion and endothelial transmigration in the microvasculature (Gregory et al., 2006; Fan et al., 2011). This was mostly dependent on Cd74 (Fan et al., 2011) and associated with enhanced $\mathrm{Ccl} 2$ secretion from microvascular ECs in vitro, without affecting endothelial Vcam1 expression in vivo (Gregory et al., 2006). In contrast, exogenous MIF upregulated ICAM1 on a human EC line in vitro (Lin et al., 2000) and reduced Icam1 expression was seen in the atherosclerotic aorta of mice treated with a Mif blocking antibody (Burger-Kentischer et al., 2006). These observations seem to be dependent on the vascular bed from which the ECs derive, as in contrast to the MIFinduced arrest responses on microvascular ECs, exogenous MIF could not induce leukocyte rolling or arrest on HUVECs. However, TNF $\alpha$-induced leukocyte rolling and adhesion on HUVECs were enhanced by exogenous MIF, which could be linked with an increase in endothelial P-selectin expression, while the TNF $\alpha$ induced expression of E-selectin, VCAM1, and ICAM1, or of different chemokines were unaltered in the presence of exogenous 
MIF (Cheng et al., 2010). Furthermore, MIF mediates neutrophil accumulation in MIF-triggered lung inflammation by inducing the chemokines $\mathrm{Cxcl} 1$ and $\mathrm{Cxcl} 2 / \mathrm{Mip} 2$ in alveolar macrophages through Cd74/extracellular signal regulated kinase (Erk) signaling (Takahashi et al., 2009) and can promote neutrophil chemotaxis in particular in the presence of actively expressed surface CD74 (Bernhagen et al., 2007). In addition, MIF has been shown to increase the surface expression of ICAM1 and VCAM1 on human monocytes via PI3K/AKT, p38, and NF-кB (Amin et al., 2006), which can be shed to soluble adhesion molecules, capable of mediating leukocyte chemotaxis (Kitani et al., 1998; Tokuhira et al., 2000). In conclusion, MIF is a pivotal mediator of leukocyte chemotaxis and arrest, by both direct mechanism or through the induction of other chemokines or adhesion molecules.

In addition to its chemotactic and arrest properties, MIF exerts pro-inflammatory and anti-apoptotic functions, either through receptor activation by extracellular MIF (as described in more detail below) or through intracellular interactions, e.g., with JAB1/CSN5 or with the pro-apoptotic proteins BIM and p53 (Kleemann et al., 2000; Jung et al., 2008; Liu et al., 2008; Noels et al., 2009). Furthermore, comparable to other CLF chemokines, MIF is secreted upon diverse inflammatory or stress factors (Table 2). This secretion occurs through a non-classical pathway, a so-called export pathway, as MIF lacks a typical N-terminal consensus secretion sequence required for classical endoplasmic reticulum/Golgimediated protein secretion (Flieger et al., 2003). Of note, MIF secretion is not only observed in immune cells, but other cell types with a prominent role in atherogenesis including ECs and SMCs can also be triggered to secrete MIF (Bernhagen et al., 1994; Noels et al., 2012).

\section{STRUCTURE - FUNCTION RELATIONSHIPS OF MIF AS A CXCR2 LIGAND}

MIF is a conserved protein, ubiquitously expressed in mammals. Furthermore, MIF homologs have been identified in avians, fish, plants (Arabidopsis thaliana), the nematode Caenorhabditis elegans, cyanobacteria, ticks, and parasites, amongst others (Calandra and Roger, 2003; Kim et al., 2010). The human and mouse MIF protein consist of 114 amino acids (excluding an $\mathrm{N}$-terminal methionine, which is processed after ribosomal synthesis), with a total molecular weight of $12.3 \mathrm{kDa}$. The human and mouse orthologs share a $90 \%$ sequence homology and lack a conventional leader sequence targeting proteins for classical secretion (Bernhagen et al., 1994). In addition to cytokine and chemokine-like activities, MIF is unusual in featuring two evolutionarily conserved catalytic activities, being an oxidoreductase and a tautomerase activity. Despite its consensus Cys-Xaa-Xaa-Cys motif, structural similarities between MIF and oxidoreductases such as thioredoxin or glutaredoxin are of remote nature only. In contrast, MIF possesses three-dimensional structural homology with the bacterial isomerases 4-oxalocrotonate-tautomerase, 5-carboxymethyl-2hydroxymuconate isomerase, and chorismate mutase (Rosengren et al., 1997; Kleemann et al., 1998; Calandra and Roger, 2003). Furthermore, MIF's overall architecture resembles that of human D-dopachrome tautomerase (D-DT). Also, MIF and D-DT share overlapping biological functions, both bind the CD74 receptor, and activate similar signaling pathways (Sugimoto et al., 1999; Merk et al., 2012). Therefore, "MIF-2" was recently suggested as an alternative name for D-DT (Merk et al., 2012). Remarkably, a MIF ortholog can even be found in the hookworm Ancylostoma ceylanicum (aceMIF), sharing 28-35\% sequence homology with human MIF. Like the human ortholog, aceMIF shows tautomerase activity, binds to CD74 and has chemoattractant properties (Cho et al., 2010). Although the global topology is similar to human MIF, protein surface and electrostatic potential are distinct (Cho et al., 2007).

The MIF monomer consists of two antiparallel $\alpha$-helices and a four-stranded $\beta$-sheet (excluding two really short $\beta$-strands), as displayed in Figure 1. Although MIF has no sequence homology to other chemokines, the 3D structure of the MIF monomer resembles the dimeric form of CXCL8 and other CXC chemokines (Weber et al., 2008) (Figure 1). But, the monomer is not the only existing form of the MIF protein. Nuclear magnetic resonance (NMR) analysis suggested that MIF dimerizes, whereas

Table 2 | MIF expression and secretion in cell types relevant in atherogenesis.

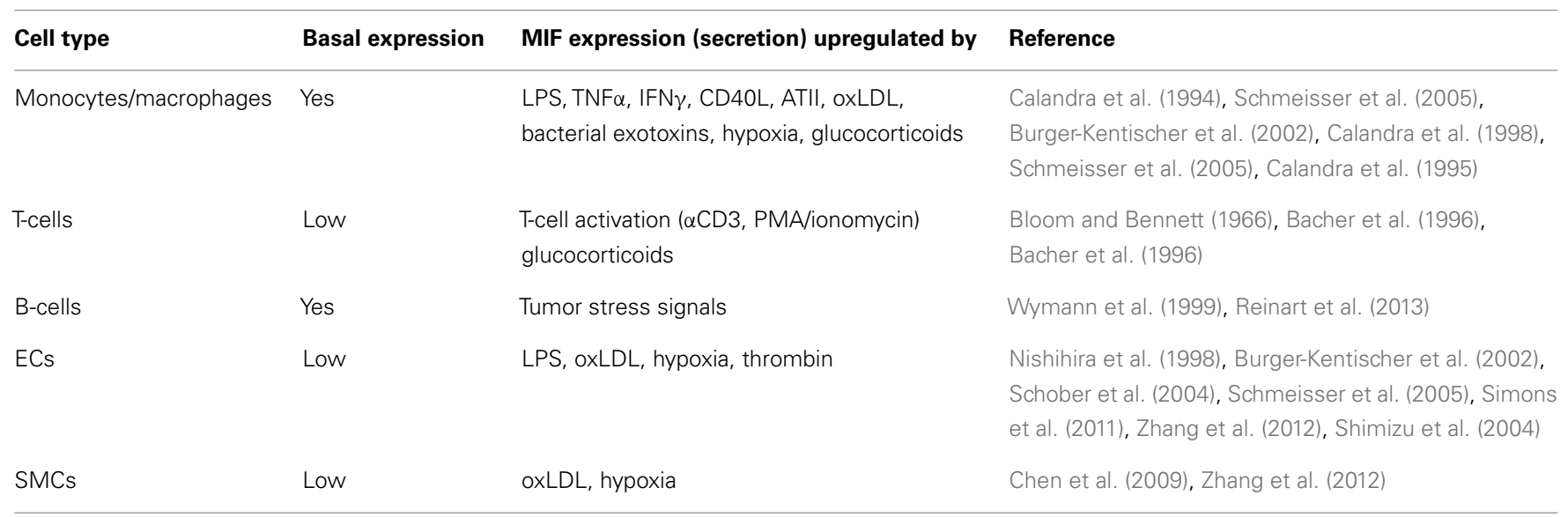

LPS, lipopolysaccharide; TNF, tumor necrosis factor; IFN, interferon; ATII, angiotensin II; oxLDL, oxidized low density lipoprotein; ECs, endothelial cells; SMCs, smooth muscle cells. 

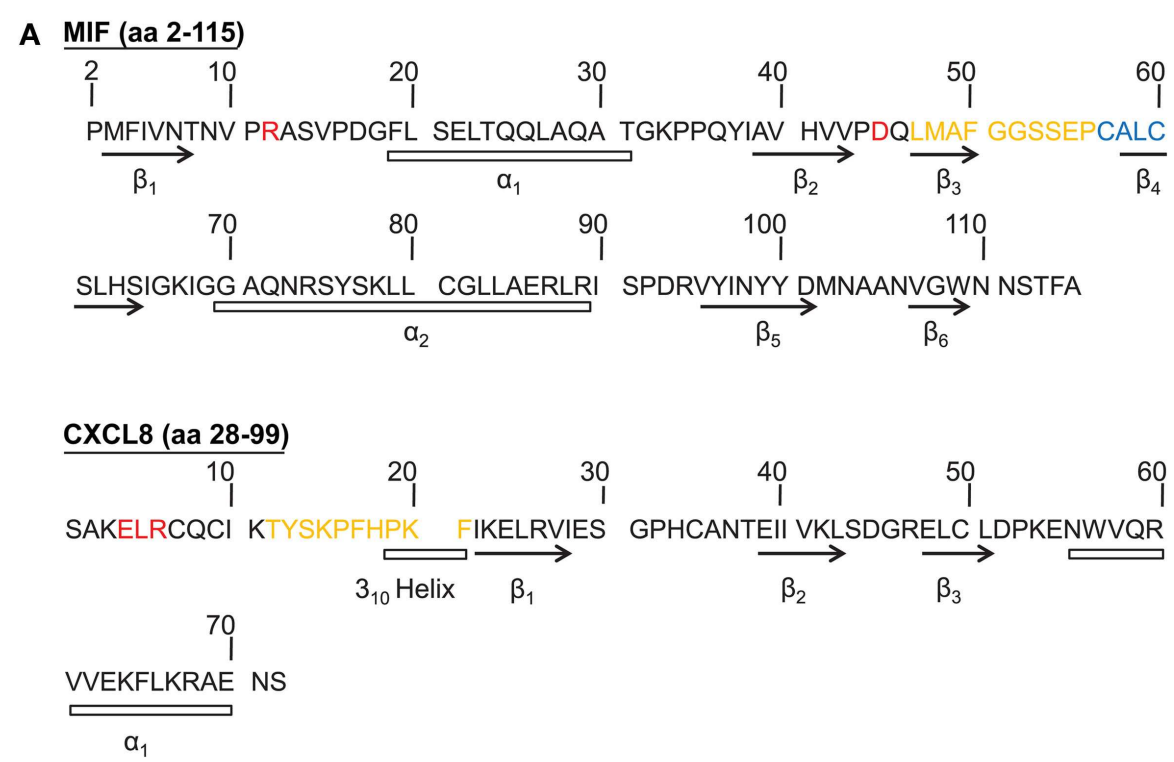

B

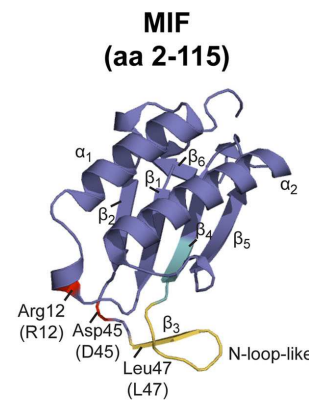

C

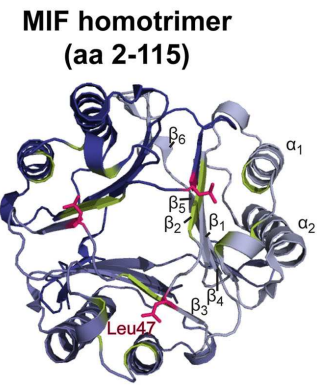

CXCL8

(aa 29-99)

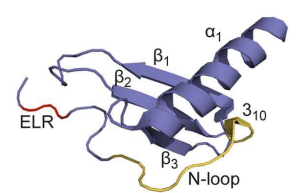

CXCL8 homodimer (aa 29-99)

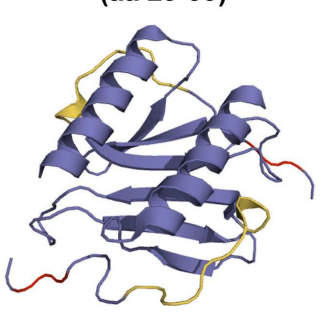

FIGURE 1 | Sequence and structure comparison of human MIF and the cognate CXCR2 ligand CXCL8. (A) Amino acid (aa) sequence comparison of MIF and CXCL8. (B,C) Comparison of the crystal structure of the MIF monomer, CXCL8 monomer, CXCL8 dimer, and MIF trimer. To (A,B): CXCL8 (aa 28-99) is the predominant form of CXCL8. $\alpha$-Helices and $\beta$-sheets are indicated. Important amino acids and motifs are highlighted: ELR or pseudo-(E)LR (red); N-loop (for CXCL8) or N-like loop (for MIF; orange); CALC motif, forming the catalytic center of MIF's oxidoreductase activity (blue). The MIF structural information is according to Orita et al. (2001), the crystal structure for CXCL8 was based on data from Clore et al. (1990). (C) Crystal structure of the MIF homotrimer (Orita et al., 2001), showing the barrel-shaped homotrimeric structure and the inter-subunit interactions between two $\beta$-strands of one subunit with $\beta$-sheets of adjacent subunits. Further stabilization is provided by the hydrophobic interaction of Leu47 (pink) of the $\beta 3$-strand of one subunit with an adjacent hydrophobic pocket (green) on a second subunit, comprising amino acids mainly positioned on the $\beta 2$-strand. For details, see text.
X-ray crystallography revealed human MIF as a trimer. The barrel-shaped homotrimeric structure is stabilized by conserved inter-subunit interactions between two $\beta$-strands of one subunit with $\beta$-sheets of adjacent subunits (Sugimoto et al., 1996; Sun et al., 1996a). Further stabilization is provided by the hydrophobic interaction of Leu47 on the $\beta 3$-strand of one subunit with an adjacent hydrophobic pocket on a second subunit, comprising amino acids mainly positioned on the $\beta 2$-strand (El-Turk et al., 2012) (Figure 1). However, X-ray and NMR structural analyses are performed at $\mathrm{mg} / \mathrm{ml}$ concentrations of the analyte, which 
are far off the physiological concentrations found in the cell or in extracellular fluids. Overall, the physiological oligomerization state of MIF remains elusive. Crosslinking studies revealed the coexistence of MIF monomers, dimers, and trimers (Sugimoto et al., 1996; Sun et al., 1996a,b), probably influenced by local MIF concentrations. At physiological conditions, an equilibrium of monomers and dimers has been described, whereas at concentrations $>10 \mu \mathrm{g} / \mathrm{ml}$, trimeric or higher-ordered oligomers seem to be preferred (Mischke et al., 1998; Calandra and Roger, 2003; Philo et al., 2004; El-Turk et al., 2008). Interestingly, homotrimeric MIF seems to drive inflammatory responses in the corneal epithelium, as recently reported by Reidy et al. (2013). Nevertheless, it is unlikely that the homotrimer is the only active form, as disruption of the homotrimeric structure with the MIF inhibitor ebselen leads to an increased chemotactic response (Ouertatani-Sakouhi et al., 2010). In addition, concentration extrapolations into the physiological $\mathrm{ng} / \mathrm{ml}$ range would likely favor a predominant population of the monomeric state. Yet, monomeric MIF is thought to be intrinsically unstable, necessitating yet unknown mechanisms for its stabilization (Bernhagen and Lue, unpublished observations).

To study the structure-activity relationship of MIF in the context of its interaction with CXCR2, it appeared obvious to look for homologous structural features with the cognate CXCR2 ligand CXCL8, which, in its dimeric form, shares structural homology with the MIF monomer (Figure 1). Bioinformatic prediction analysis in conjunction with mutational studies revealed an important receptor interacting motif in MIF that resembles the $\mathrm{N}$ terminal Glu-Leu-Arg (ELR) motif carried by a sub-group of CXC chemokines, as shown for CXCL8. This MIF motif, consisting of Asp45-X-Arg12, was termed "pseudo-(E)LR" motif, as the glutamate $(\mathrm{Glu} / \mathrm{E})$ was substituted with an aspartic acid (Asp/D) (Hebert et al., 1991; Weber et al., 2008). The non-adjacent residues of this pseudo-(E)LR motif are located in neighboring loops of the MIF protein with similar spacing as in the true ELR motif (Figure 1). Site-directed mutagenesis studies showed an almost complete inhibition of CXCR2 binding when the R12A or D45A mutation was introduced into MIF. The MIF-R12A mutant also exhibited a complete loss of chemotactic and arrest function. Also, the MIF-D45A mutant showed a reduced chemotactic and arrest activity in in vitro assays, whereas its hyperactivity towards neutrophil recruitment in a peritonitis model was shown to be CXCR4-mediated (Weber et al., 2008). Furthermore, evidence became available for an interaction of the pseudo-(E)LR motif with the extracellular loops EL-2 and EL-3 of CXCR2 (Kraemer et al., 2011). Still, it should be noted that Arg12 and Asp45 of the pseudo-(E)LR motif are located close to the critical Leu47 residue, which is involved in inter-subunit hydrophobic interactions modulating the conformation and stability, but not the oligomerization state, of homotrimeric MIF (El-Turk et al., 2012) (Figure 1). The reduced leukocyte adhesion activity, which was observed for the pseudo-(E)LR mutants (Weber et al., 2008), might thus not solely result from changes in the direct MIF receptor interaction locus, but could also result in part from modifications of the conformational stability of MIF by disturbance of the Leu47 region.

Interestingly, Kraemer et al. (2011) revealed the involvement of an N-like loop in MIF in binding to CXCR2. This loop spans 10 amino acids from position 47 to 56 but is structurally different
Table 3 |The N-like loop of MIF shows only limited similarity with the $\mathrm{N}$-loop of CXC chemokines.

\begin{tabular}{ll}
\hline Chemokine & N-loop sequenc \\
\hline CXCL1 1 & LQTLQ GIHP \\
CXCL2 2 LILQ GIHL \\
CXCL3 3 LILQ GIHL \\
CXCL5 5 LTT GVHP \\
CXCL6 & L 5 LRVTL RVNP \\
CXCL7 7 IKTTS GIHP \\
CXCL8 & IKTYSKPFHP \\
MIF & LMAFGGSEP
\end{tabular}

Adapted from Kraemer et al. (2011).

from the N-loop of CXC chemokines (Figure 1; Table 3). Whereas the classical N-loop found in CXC chemokines contains 1-3 basic residues and interacts with the $\mathrm{N}$-terminus of the receptor, the $\mathrm{N}$-like loop of MIF has an acidic isoelectric point (pI) and interacts with EL-1 and parts of EL-2 as well as with the N-terminus of CXCR2, according to peptide spot array analysis. Importantly, short MIF N-like loop-derived peptides blocked monocyte arrest and inhibited MIF/CXCR2 interaction in a receptor competition assay, verifying the importance of the N-like loop of MIF for CXCR2 binding (Kraemer et al., 2011). Furthermore, amino acids in the region between residues 50 and 68 are critical for obtaining potent MIF neutralizing antibodies, which block important biological activities such as cell proliferation and glucocorticoid overriding in vitro and MIF-driven septic responses in vivo (Kerschbaumer et al., 2012). This confirmed that the N-like loop region of MIF is critical for MIF-driven receptor-mediated processes. Moreover, site-specific mutations of the cysteines at positions 57 and 60 and the use of peptides covering the region 50-65 further underscored that the sequence region of the $\mathrm{N}$-like loop, i.e., region 47-68, is critical for a variety of MIF activities (Kleemann et al., 1998, 1999; Nguyen et al., 2003).

Taken together, as suggested by Kraemer et al. (2011), the binding of MIF to CXCR2 seems to follow a two-site-binding mechanism which is similar but not identical to that between CXCL8 and CXCR2. In contrast, no structure-activity relationship data are available yet for the interaction between MIF and its receptors CD74 and CXCR4. Interesting questions are therefore, whether the uncovered motifs mediating the MIF/CXCR2 interaction are also important for the interaction between MIF and CXCR4, whether for CD74 binding fully different regions are required, and whether CXCR7, for which an interaction with MIF has recently been implied, binds directly to MIF and utilizes the N-like loop and pseudo-(E)LR motif as well.

Interestingly, the anti-inflammatory drug AV411 (Ibudilast) and its analog AV1013, both allosteric inhibitors of MIF's tautomerase activity, were found to inhibit MIF-mediated CXCR2dependent chemotaxis of monocytes (Cho et al., 2010). AV1013 binds into a pocket formed by several C-terminal residues of MIF. AV1013 binding apparently induces conformational changes leading to both an inactivation of the tautomerase site and changes at the MIF/CXCR2 interface, i.e., likely affecting the N-like loop 
or pseudo-(E)LR motif. Alternatively, conformational changes in the tautomerase site could subsequently lead to conformational changes in the receptor interaction interface of MIF (Cho et al., 2010). Similarly, the hormonally inert isomer DT(4) of the thyroid hormone thyroxine [T(4)], inhibited MIF's tautomerase activity by binding to a hydrophobic pocket harboring this enzymatic function and reduced leukocyte accumulation in a carrageenaninduced airpouch model in wildtype but not $\mathrm{Mif}^{-/-}$mice, providing further evidence for a potential participation of the tautomerase site in MIF receptor-mediated chemotaxis (Al-Abed et al., 2011). Yet, disruption of the MIF trimer, and therefore of the active tautomerase site ${ }^{2}$, increased MIF-mediated chemotaxis (Ouertatani-Sakouhi et al., 2010). In addition, FingerleRowson et al. (2009) showed that the tautomerase-inactive mutant P2G-MIF, which contains a mutation of the crucial catalytic Nterminal Proline (Pro2) ${ }^{3}$, could still bind CD74 and mediate growth regulation in a skin tumorigenesis model, although to a somewhat reduced level. This indicates that the enzyme activity per se is not essential for CD74 receptor binding. Also, in comparison with wildtype MIF, the capacity of P2G-MIF to compete with CXCL8 for binding to CXCR2-expressing cells was more reduced than ligand competition in the CD74 binding assay (FingerleRowson et al., 2009). This suggests that the Pro2 residue and/or conformational changes in the tautomerase site affect MIF binding to CXCR2 more than the MIF-CD74 interaction.

\section{MIF'S ARREST FUNCTION THROUGH ITS RECEPTOR CXCR2}

MIF, immobilized on the endothelial surface, triggers the arrest of monocytes/neutrophils and T-cells through CXCR2 and CXCR4, respectively, by a rapid and transient activation of the leukocyte integrins LFA1 and VLA4 (Box 3) (Bernhagen et al., 2007). While the precise mechanism of MIF deposition on ECs has not yet been explored, the basic pI could be a likely explanation. Alternatively, ECs express CD74 which has been found to be modified by chondroitin sulfate, thus providing a possible anchoring site for MIF as well.

For immobilized classical chemokines, the GPCR/G $\alpha$ imediated intracellular signaling cascade in leukocytes triggering integrin activation and leukocytic arrest, has been shown to be very complex, with currently 65 proteins identified to be possibly involved (Ley et al., 2007; Montresor et al., 2012). Three main stages of integrin activation are distinguished. These involve: (1) phospholipase C (PLC)-mediated calcium influx, (2) small GTPases, and (3) actin-binding proteins as talin-1 and kindlin3, as described in more detail elsewhere (Ley et al., 2007; Lefort and Ley, 2012; Montresor et al., 2012) (Figure 2). However, this model of GPCR-mediated integrin activation cannot be universally applied to all conditions, and it is expected to be dependent on the GPCR, GPCR ligand, the integrin activated, and the biological context (Ley et al., 2007; Montresor et al., 2012). For

\footnotetext{
${ }^{2}$ MIF tautomerase activity requires trimerization.

${ }^{3}$ In the paper by Fingerle-Rowson et al. (2009), MIF sequence numbering refers to the processed MIF protein after Metl removal. Thus, the protein sequence of MIF in that paper starts with Pro1 rather than Pro2, the latter referring to the cDNA sequence. In the current article, we prefer to refer to this proline residue as Pro2, i.e., applying the numbering according to the cDNA sequence to be consistent with the sequence numbering of the mutants above.
}

MIF/CXCR2, few details are known about the exact molecular delineation of proteins involved in MIF receptor-mediated integrin activation. Initial inhibitor studies revealed MIF to mediate monocyte and T-cell adhesion by Gai proteins and PI3K (Bernhagen et al., 2007), a kinase which is directly activated by the $G \beta \gamma$ dimer and which mediates adhesion stabilization of neutrophils to CXCL1 through CXCR2 (Smith et al., 2006). Also, MIF triggered CXCR2-dependent calcium transients. In mouse fibroblasts, recombinant MIF induces the activation of RhoA GTPase and Rho kinase, and Mif-deficient fibroblasts showed a reduction in RhoA GTPase activation and stress fiber formation (Swant et al., 2005). Of note, the latter has been linked with integrin clustering (Roovers and Assoian, 2003). Also VASP, LASP-1, IQGAP1, and NHERF1 were recently identified to interact with CXCR2 and to be involved in CXCL8-triggered chemotaxis (Neel et al., 2009, 2011; Wu et al., 2012), but it remains unknown whether this is directly linked to integrin activation, or whether these proteins are also involved in MIF/CXCR2-mediated arrest.

In addition to this direct link of MIF-CXCR2 signaling towards integrin activation, MIF has been shown to induce the migration of human chondrosarcoma cells by upregulating the transcription of the $\alpha_{\mathrm{v}} \beta_{3}$ integrin through PI3K/AKT/NF- $\mathrm{BB}$ signaling in a CXCR2- and CXCR4-mediated way (Lee et al., 2012). This again indicates MIF's potential to mediate chemokine-like functions through indirect effects, by regulating the expression of proteins involved in leukocyte adhesion, as discussed previously.

\section{CD74 AND CXCR4 AS ALTERNATIVE MIF RECEPTORS CD74}

In 2003, the CD74 protein was discovered as a high affinity receptor for MIF (Leng et al., 2003). CD74 is well-known as an MHC class II chaperone, as it is the membrane-expressed portion of the invariant chain (II), which typically regulates antigenic peptide loading to MHC class II proteins through its CLIP domain. However, CD74 can also be expressed in the absence of the MHC class II protein, thus executing functions as membrane receptor (Borghese and Clanchy, 2011). The CD74 receptor is a type II membranespanning protein with a short cytoplasmic $\mathrm{N}$-terminus. As a result, accessory signaling molecules like Src, CD44, c-Met, or other coreceptors are necessary to mediate CD74 signaling by MIF, i.e., by forming a functional receptor-tyrosine-kinase-(RTK)-like complex (Bernhagen et al., 2007; Gordin et al., 2010). Signaling of MIF through CD74 has been linked with MIF's pro-inflammatory and anti-apoptotic functions. For instance, interaction of MIF with CD74 leads to the activation of MAPKs and other protein kinases. One example is the sustained and transient activation of the MAPK ERK1 and ERK2 (Lue et al., 2006; Shi et al., 2006). Sustained ERK activation is mediated by CD74/CD44 and protein kinase $\mathrm{A}$ and has been linked to cell proliferation and enhanced pro-inflammatory phospholipase A2 activity (Mitchell et al., 1999; Lue et al., 2006; Shi et al., 2006). Recently, also $\beta$-arrestin-1 was shown to be involved in MIF-triggered sustained ERK activation, mediating MIF internalization in a CD74- and clathrin-dependent manner (Xie et al., 2011). Another example is the effect of MIF and CD74 on the MAPK Jun N-terminal kinase (JNK). MIF either impedes JNK signaling and JNK-mediated apoptosis, or rapidly initiates JNK activation through CXCR4/CD74, activating the 


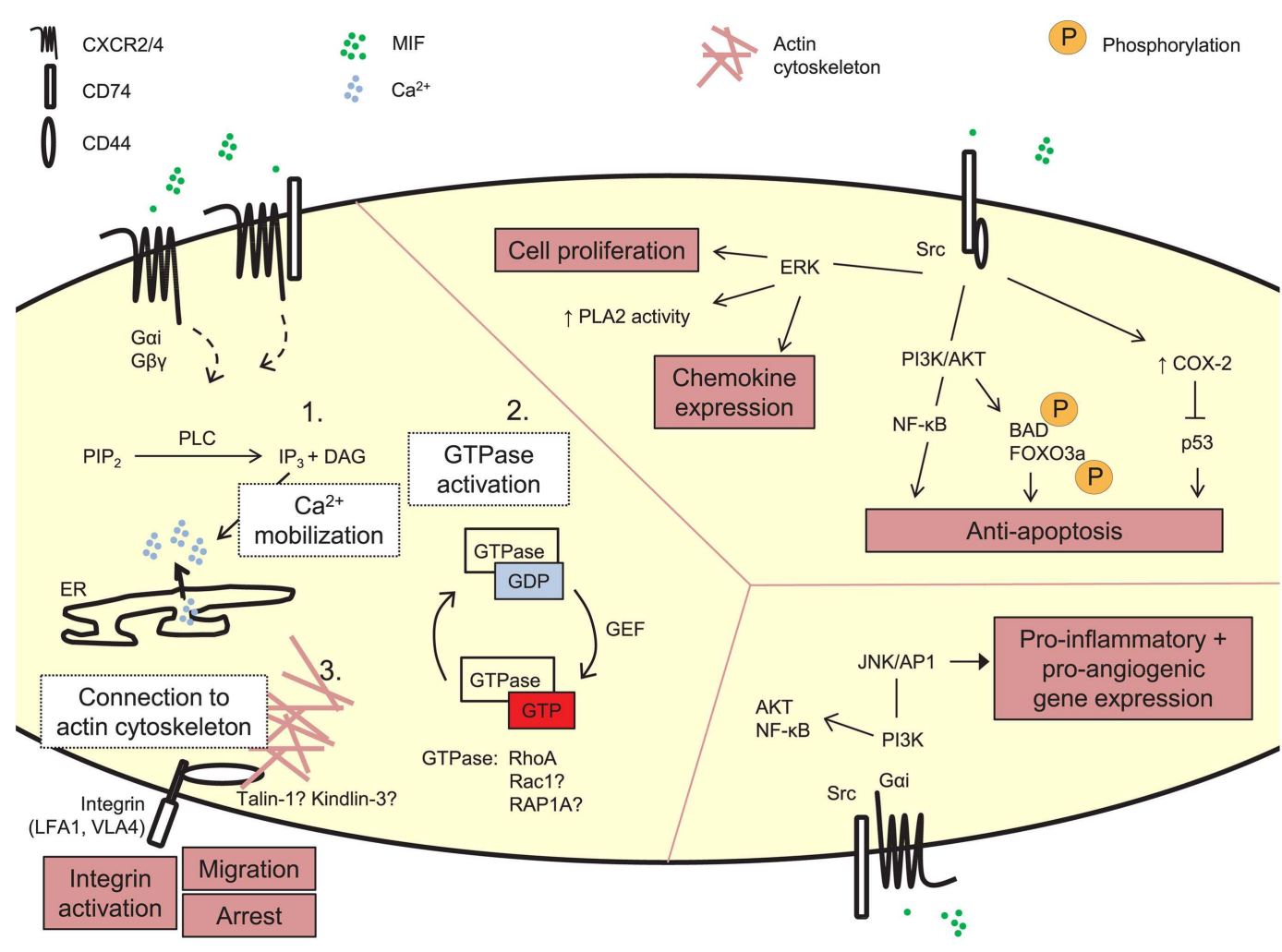

FIGURE 2 | Signaling by exogenous MIF. MIF can induce signaling cascades through its receptors CD74, CXCR2, and CXCR4. These pathways underlie MIF's biological functions, e.g., leukocytic integrin activation, cell proliferation, and anti-apoptosis, induction of pro-inflammatory gene expression. The detailed molecular mechanism underlying MIF's arrest function through its receptors CXCR2 and CXCR4 is still unexplored. Three main steps in GPCR-mediated integrin activation can be distinguished, i.e., PLC-mediated calcium mobilization, activation of small GTPases and recruitment of actin-binding proteins linking the integrin to the actin cytoskeleton. PIP2, phosphatidylinosytol 4,5-biphosphate; PLC, phospholipase C; IP3, inosytol 1,4,5-triphosphate; DAG, diacylglycerol; $\mathrm{Ca}^{2+}$, calcium; ER, endoplasmic reticulum; GDP, guanosine diphosphate; GTP, guanosine triphosphate; guanine nucleotide exchange factor; PLA2, phospholipase A2; ERK, extracellular signal-related

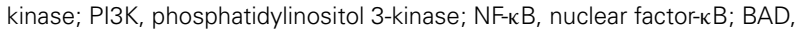
BCL2-associated agonist of cell death; FOXO3A, forkhead box O3a; COX-2, cytochrome $\mathrm{C}$ oxidase subunit 2; JNK, c-Jun N-terminal kinase; AP1 (c-Jun), activator protein-1.
Src/PI3K/JNK/AP1 pathway, which results in the expression of the pro-inflammatory protein CXCL8 (Kleemann et al., 2000; Qi et al., 2009; Lue et al., 2011). Also, MIF-CD74 signaling has been shown to promote B-cell survival through CD44/PI3K/AKT-mediated NF- $\kappa \mathrm{B}$ activation and NF- $\kappa \mathrm{B}$-induced CXCL8 secretion (Binsky et al., 2007; Gore et al., 2008). Furthermore, a CD74/Src/PI3K/AKT pathway links MIF to the phosphorylation of the pro-apoptotic proteins $\mathrm{BAD}$ and $\mathrm{FOXO} 3 \mathrm{a}$, providing a survival signal (Lue et al., 2007). Also, cyclooxygenase (COX)-2, which prevents the accumulation of p53, can be upregulated through this pathway, likewise contributing to survival (Mitchell et al., 2002).

In addition, CD74 has been shown to be involved in MIFmediated leukocyte chemotaxis and arrest, although not in all circumstances. The administration of a CD74 blocking antibody reduced the MIF-dependent monocyte arrest on ex vivo carotid arteries from atherosclerotic mice (Bernhagen et al., 2007), and activation of macrophage CD74 by MIF leads to an ERK1/2dependent release of $\mathrm{Cxcl} 1$ and $\mathrm{Cxcl} 2$, mediating the MIF-induced accumulation of neutrophils in the alveolar space (Takahashi et al., 2009). Furthermore, Ccl2-triggered monocyte arrest and endothelial transmigration were severely decreased in Mif- and Cd74-deficient mice. Mif- and Cd74-deficient macrophages also showed a reduced $\mathrm{Ccl} 2$-triggered chemotaxis in vitro, which was associated with a reduced Rho GTPase and Mapk activation. However, Mif-deficient macrophages showed a lower expression of the $\alpha_{4}$ integrin and of the Mapk-regulating protein Mkp1, which was not the case for Cd74-deficient macrophages, suggesting that the involvement of endogenous Mif and Cd74 in $\mathrm{Ccl} 2$-induced monocyte recruitment or adhesion could at least partially be mediated through distinct mechanisms. Furthermore, exogenous MIF could restore deficient Ccl2-triggered leukocyte adhesion, but not endothelial transmigration, in $\mathrm{Mif}^{-1-}$ and $C d 74^{-1-}$ mice to the same extent, indicating that exogenous MIF enhances CCL2-mediated leukocyte adhesion mostly independently of CD74. In contrast, exogenous MIF-induced leukocyte adhesion and transmigration were severely impaired in $C d 74^{-1-}$ mice (Fan et al., 2011), suggesting an alternative mechanism underlying MIF- versus CCL2/MIF-induced leukocyte adhesion in vivo. Alternatively, these different observations could result from differentially targeting vascular versus 
leukocytic cells to a different degree, when examining MIFinduced versus CCL2/MIF-induced leukocyte adhesion, respectively. Of note, MIF also desensitized CCL2-mediated chemotaxis (Hermanowski-Vosatka et al., 1999), implying a MIF/CXCRmediated cross-signaling mechanism as known for classical chemokines.

\section{CXCR4}

Another chemokine receptor known to interact with MIF is CXCR4, as shown by Bernhagen et al. (2007). Prior to this finding, the CXCL12/CXCR4 interaction was thought to be highly specific, from the receptor as well as from the ligand site (Murphy et al., 2000). The MIF/CXCR4 interaction together with the identification of the CXCL11 receptor CXCR7 as an additional receptor for CXCL12 (Balabanian et al., 2005; Burns et al., 2006; Thelen and Thelen, 2008), disproved the existence of a nonpromiscuous interaction. In fact, CXCR4 is also known to interact with the HIV gp120 protein and a recent report suggests that serum ubiquitin also interacts with CXCR4 (Saini et al., 2010). CXCR4 is widely expressed, particularly on many cell types of the immune system (Murphy et al., 2000) (Table 4). The knockout of Cxcr4 in mice is embryonically lethal, due to defects in hematopoiesis, vasculo-, cardio-, and neurogenesis (Ma et al., 1998; Zou et al., 1998). CXCR4 has prominently been implicated in cell recruitment processes, with CXCL12 mediating the recruitment of hematopoietic and vascular progenitor cells from the bone marrow (Mohle et al., 1998; Sainz and Sata, 2007). On the other hand, MIF has been shown to induce T-cell recruitment and arrest through CXCR4-induced, rapid $\alpha_{4} \beta_{1}$ (VLA4) integrin activation
(Bernhagen et al., 2007). MIF was also identified as the critical autocrine CXCR4 ligand driving cell invasion by drug-resistant colon carcinoma HT-29 cells (Vera et al., 2008; Dessein et al., 2010). Little is known about the molecular details of MIF/CXCR4 signaling. In T-cells, MIF stimulation increases CXCL8 expression through both CXCR4 and CD74, depending on Src, PI3K, and JNK phosphorylation (Lue et al., 2011). Earlier on, CXCR4/CD74 heterodimers were found in monocytes, T-cells and fibroblasts, and MIF-induced AKT signaling was shown to be reduced both by blocking CD74 and CXCR4, indicating a functional CXCR4/CD74 MIF receptor complex (Schwartz et al., 2009).

\section{CXCR7}

Tarnowski et al. (2010) implicated a recently identified chemokine decoy receptor in MIF internalization and MIF-dependent adhesion of rhabdomyosarcoma cells. This seven-transmembranereceptor, encoded by the $R D C-1$ gene, was named CXCR7 and characterized as a receptor for CXCL11 and CXCL12 (Balabanian et al., 2005; Burns et al., 2006). CXCR7 is expressed on a variety of cells, including leukocytes, activated ECs, mature neurons, CD $34^{+}$progenitor cells, and several tumor cell lines (Balabanian et al., 2005; Burns et al., 2006; Infantino et al., 2006; Zabel et al., 2009; Hattermann et al., 2010; Tarnowski et al., 2010; Shimizu et al., 2011). Unlike the prototypical chemokine receptors, CXCR7 carries two amino acid substitutions in the DRYLAIV motif (A/S and $\mathrm{V} / \mathrm{T}$ ) on the second intracellular loop, resulting in a change in the adaptor motif for $G$ proteins and thus to a loss of $G$ protein signaling (Zabel et al., 2009). Even though typical chemokine receptor signaling pathways, like calcium mobilization, are absent

Table 4 | MIF receptor expression in cell types relevant in atherogenesis.

\begin{tabular}{|c|c|c|c|}
\hline Cell type & Receptor & Remark & Reference \\
\hline \multirow[t]{3}{*}{ Monocytes/macrophages } & CXCR2 & & Murphy et al. (2000) \\
\hline & CXCR4 & & $\begin{array}{l}\text { Murphy et al. (2000), Sunderkotter et al. (2004), } \\
\text { Ingersoll et al. (2010) }\end{array}$ \\
\hline & CD74 & & Martin-Ventura et al. (2009) \\
\hline Neutrophils & CXCR2 & & Murphy et al. (2000) \\
\hline \multirow[t]{3}{*}{ T-cells } & CXCR4 & & Murphy et al. (2000) \\
\hline & CXCR2 & On some $\mathrm{CD} 8^{+} \mathrm{T}$-cells, not on $\mathrm{CD} 4^{+} \mathrm{T}$-cells & Chuntharapai et al. (1994) \\
\hline & $C D 74$ & On a subset of activated T-cells & Stein et al. (2007) \\
\hline B-cells & No CXCR2 & & Chuntharapai et al. (1994) \\
\hline \multirow{2}{*}{ ECs } & CXCR4 & & Gupta et al. (1998) \\
\hline & CD74 & Only upregulated under inflammatory stimulation & Stein et al. (2007) \\
\hline \multirow[t]{3}{*}{ SMCs } & CXCR2 & & Govindaraju et al. (2006) \\
\hline & CXCR4 & & Schecter et al. (2001) \\
\hline & CD74 & In atherosclerotic plaques & Martin-Ventura et al. (2009) \\
\hline
\end{tabular}

ECs, endothelial cells; SMCs, smooth muscle cells. 
for CXCR7, other signaling cascades have been described. For example, the $\beta$-arrestin-dependent internalization of chemokines by CXCR7 results in the activation of MAPK signaling and the CXCL12/CXCR7 interaction promotes Gai-independent ERK and AKT phosphorylation, mediating T-cell chemotaxis and survival (Balabanian et al., 2005; Rajagopal et al., 2010; Kumar et al., 2012), although these findings have been controversial in part. On the other hand, CXCL11 binding to CXCR7 inhibits the CXCL12/CXCR4-mediated transendothelial migration of breast cancer cells (Dambly-Chaudiere et al., 2007; Boldajipour et al., 2008; Zabel et al., 2009). Thus, CXCR7 might play a role in MIF-mediated chemotaxis by generating MIF gradients leading to differential signaling, act as a co-receptor or influence chemokine crosstalk. Whether CXCR7 is implicated in a direct interaction with MIF or whether the observed effects by Tarnowski et al. (2010) are based on an indirect interaction, for instance by forming a functional complex with CXCR4 as identified by Luker et al. (2009), will have to be elucidated in the future. Nevertheless, the interaction of MIF with CXCR7 might be a further fine-tuning mechanism in the complex chemokine/chemokine receptor system.

\section{RECEPTOR OLIGOMERIZATION}

Receptor oligomerization is a further possibility to modulate ligand affinity, ligand internalization and signal transduction with an impact on cellular processes like cell arrest or cell activation. It is well established that chemokine receptors form dimers or even higher-order oligomers (Milligan, 2007; Thelen et al., 2010; Kraemer et al., 2013). Also, the MIF receptors CXCR2 and CXCR4 have been shown to homodimerize and even multimerize in a ligandindependent manner (Trettel et al., 2003; Hamatake et al., 2009; Wu et al., 2010). Moreover, CXCR2 and CXCR4 heterodimerize with various CXC receptors. For example, the MIF receptors CXCR4 and CXCR7 form a complex, thus modulating CXCL12-mediated CXCR4-dependent chemotaxis (Thelen and Thelen, 2008; Levoye et al., 2009). Also, CXCR2 heterodimerizes with CXCR1 (Wilson et al., 2005). Heterocomplex formation is not solely restricted to receptors of the same sub-family, but also exists between different chemokine receptor subtypes (Kraemer et al., 2013). The cooperation of the CXCR4 and CCR5 receptor, for example, is required for chemokine-induced T-cell stimulation at the immunological synapse (Contento et al., 2008). Furthermore, complexes between chemokine receptors and other receptor types were observed. As such, CXCR4 engages with the dopamine receptor and for CXCR2, a complex with the $\delta$-opiod receptor (DOP) was demonstrated (Parenty et al., 2008; Kraemer et al., 2013). Interestingly, the CD74 receptor interacts with both CXCR2 and CXCR4 (Bernhagen et al., 2007; Schwartz et al., 2009). CXCR2/CD74 heterodimers are implicated in leukocyte recruitment. In this context, it was suggested that CD74 amplifies MIF/CXCR2-mediated signaling, as neutrophils, which lack CD74, only show a weak migratory response to MIF, whereas HL-60 cells, which do not express detectable levels of CD74, increasingly migrate to MIF after ectopic CD74 expression (Bernhagen et al., 2007). CXCR4/CD74 heterodimers were found in monocytes, T-cells, and fibroblasts. Both CXCR4 and CD74 mediate MIF-induced AKT signaling and a fast and transient activation of the JNK/AP1 pathway, suggesting the existence of a functional heterocomplex (Schwartz et al., 2009; Lue et al., 2011). Taken together, MIF/CXCR interactions play a role in inflammation and inflammatory leukocyte recruitment and arrest. The possibility that MIF interacts not only with a single receptor, but with a complex of receptors could further add to a highly controlled cell-, site- and disease-stage specific inflammatory cell adhesion process.

\section{MIF IN ATHEROSCLEROSIS}

Atherosclerosis is caused and sustained by inflammatory processes in the vessel wall. The deposition and oxidation of low density lipoprotein (LDL) in the intima drives EC and SMC activation, and the recruitment and infiltration of leukocytes (Weber and Noels, 2011). Whereas MIF is only detectable at low levels in healthy vessels, hyperlipidemia strongly enhances MIF expression in ECs, SMCs, monocytes, and T-cells in atherosclerotic lesions (Lin et al., 2000; Burger-Kentischer et al., 2002, 2006), and an even further upregulation during atheroprogression suggested a role for MIF in plaque destabilization (Burger-Kentischer et al., 2002) (Table 5). In vitro, leukocytes and vascular cells have been shown to express MIF upon several inflammatory triggers (Table 2). Typically, an initial secretion pulse of preformed MIF protein precedes MIF transcription (Simons et al., 2011). Also, all cell types involved in atherogenesis, including monocytes/macrophages, neutrophils, B- and T-lymphocytes, ECs, and SMCs, express at least one of the MIF receptors CD74, CXCR2, or CXCR4 (Table 4), suggesting that they do not solely act as MIF storage pools, but also respond to secreted MIF.

Of note, functional animal studies confirmed an atheroprogressive role of MIF, showing a reduced lesion size and inflammatory profile in Mif-deficient mice, or after treatment with a Mif blocking antibody (Table 5) (Pan et al., 2004; Burger-Kentischer et al., 2006; Bernhagen et al., 2007; Verschuren et al., 2009). Remarkably, Mif blockade even induced a regression of established atherosclerotic lesions (Bernhagen et al., 2007). Similarly, Mif neutralization reduced injury-induced restenosis, in which Mif expression is initially upregulated in SMCs, and in ECs and foam cells in a later stage (Chen et al., 2004; Schober et al., 2004).

These atheroprogressive effects of MIF can be linked with MIF's potential to trigger the expression of inflammatory mediators and mediate leukocyte recruitment and arrest directly or through the induction of adhesion molecules and chemokines in ECs and monocytes/macrophages (Figure 3) (Bernhagen et al., 1994; Calandra et al., 1994, 1995; Lan et al., 1997; Lin et al., 2000; Amin et al., 2006; Gregory et al., 2006, 2009; Takahashi et al., 2009; Cheng et al., 2010). Furthermore, the ability of MIF to stimulate oxidized LDL (oxLDL) uptake by macrophages (Atsumi et al., 2000), and its association with protease expression and a reduced PDGFBB-induced SMC migration (Pan et al., 2004; Schrans-Stassen et al., 2005; Verschuren et al., 2005) may further contribute to MIF's plaque destabilizing properties in hyperlipidemia-induced atherogenesis. In the context of injury-induced neointima formation, interference with MIF's anti-apoptotic effect could underlie the enhanced apoptosis in conditions of Mif antibody treatment (Mitchell et al., 2002; Chen et al., 2004), whereas a report on MIF driving SMC proliferation could be linked to a decreased medial cell proliferation under conditions of MIF blockade (Chen et al., 2004). 


\section{Reference}

\section{MIF EXPRESSION IN ATHEROSCLEROSIS AND RESTENOSIS}

Native or diet-induced atherosclerosis

Rabbit Upregulated in macrohages, ECs, and SMCs from early atherosclerotic lesions

Apoe ${ }^{-l-}$ mouse Enhanced in all cell types (monocytes, T-cells, ECs, SMCs), but mostly in monocytes

Human
Enhanced in all cell types (monocytes, T-cells, ECs, SMCs)

Further upregulated upon progression
Lin et al. (2000)

Burger-Kentischer et al. (2006)

Burger-Kentischer et al. (2002)

Injury-induced restenosis

Apoe ${ }^{-l--} ; L d l r^{-/} \quad$ Upregulated in medial SMCs (early) and ECs and foam cells (late)

Chen et al. (2004), Schober et al. (2004)

\section{EFFECTS OF MIF BLOCKADE ON ATHEROSCLEROSIS IN MICE}

Native or diet-induced atherosclerosis

Pan et al. (2004)

Reduced cell proliferation

Reduced cathepsin expression

Mif ${ }^{-1-} ;$ Ldlr $^{-1-} \quad$ Chow diet

Reduced lesion size

Verschuren et al. (2009)

Apoe $^{-1-} \quad$ Chow diet

Reduced macrophage content

+Mif blocking $\mathrm{Ab}$

Only non-significant reduction in aortic lesion size

Burger-Kentischer et al. (2006)

Reduced macrophage content

Reduced aortic expression of pro-inflammatory

markers (CD40L, TNF $\alpha$, IL12, ICAM1), the transcription

regulators C-EBP $\beta$ and phospho-cJun, and of MMP2

Atherosclerotic

High-fat diet

Regression in established lesions

Bernhagen et al. (2007)

Apoe $^{-1-}+$ Mif

Reduced macrophage and T-cell content

blocking $\mathrm{Ab}$

Injury-induced restenosis

Ldlr ${ }^{-1-} \quad$ Experimenta

Reduced neointimal size

Chen et al. (2004)

+ Mif blocking $\mathrm{Ab}$

angioplasty

Reduced leukocyte recruitment

Reduced cell proliferation in media and neointima

Increased apoptosis in media and neointima

Apoe $^{-/-} \quad$ Wire injury

No significant effect on neointimal size

Schober et al. (2004)

+ Mif blocking $\mathrm{Ab}$

Reduced macrophage content

Increased SMC and collagen content

\section{HUMAN EPIDEMIOLOGICAL STUDIES}

MIF SNP rs755622 (-173 CC genotype) risk factor for CHD and diverse inflammatory diseases

Although not confirmed by all studies

Donn et al. (2001), Herder et al. (2008)

Palomino-Morales et al. (2010)

MIF-173 CC genotype more frequent in Turkish children with cardiomyopathy

Col-Araz et al. (2012)

MIF SNP rs1007888 (GG genotype) associated with enhanced MI risk in female Czech patients

Tereshchenko et al. (2009)

Enhanced MIF plasma levels predictive for enhanced heart failure in CHD patients with impaired

glucose tolerance or type 2 diabetes mellitus

Makino et al. (2010)

Increased MIF plasma levels in patients with ACS, associated with inflammatory marker expression

(CRP, IL6)

\section{INFLAMMATORY/CARDIOVASCULAR EFFECTS OF MIF}

Monocytes/macrophages

Enhances direct monocyte recruitment and arrest through CXCR2

Enhances CCL2-induced monocyte recruitment

Bernhagen et al. (2007)

Enhances oxLDL uptake and degradation

Fan et al. (2011)

Atsumi et al. (2000) 


\begin{tabular}{|c|c|c|}
\hline & & Reference \\
\hline Induces inflammatory mediators & $\mathrm{TNF} \alpha, \mathrm{IL} 1 \beta, \mathrm{IL6}, \mathrm{IL} 8$ & $\begin{array}{l}\text { Bernhagen et al. (1994), Calandra et al. } \\
\text { (1994, 1995), Lan et al. (1997) }\end{array}$ \\
\hline \multicolumn{2}{|c|}{ Enhances expression of chemokines and adhesion molecules } & Amin et al. (2006), Takahashi et al. (2009) \\
\hline \multicolumn{2}{|c|}{ Interferes with p53-mediated apoptosis } & Mitchell et al. (2002) \\
\hline \multicolumn{3}{|l|}{ SMCs } \\
\hline \multicolumn{2}{|c|}{ Mif-/- SMCs: reduced cathepsin expression, reduced elastin/collagen degradation capacity } & Pan et al. (2004) \\
\hline \multicolumn{2}{|c|}{ Inhibits long-term PDGF-BB-induced SMC migration, despite short-term stimulatory effect } & Schrans-Stassen et al. (2005) \\
\hline \multicolumn{2}{|c|}{ Drives SMC proliferation in some studies (but not all) } & $\begin{array}{l}\text { Chen et al. (2004), Schrans-Stassen et al. } \\
\text { (2005) }\end{array}$ \\
\hline \multicolumn{3}{|c|}{ Other } \\
\hline \multicolumn{2}{|c|}{ Colocalizes with MMP1/9 in human vulnerable plaques } & Kong et al. $(2005 a, b)$ \\
\hline \multicolumn{2}{|l|}{ Pro-angiogenic } & $\begin{array}{l}\text { Chesney et al. (1999), Ogawa et al. } \\
\text { (2000); Amin et al. (2003) }\end{array}$ \\
\hline
\end{tabular}

Apoe, apolipoprotein E; Ldlr, low density lipoprotein receptor; ECs, endothelial cells; SMCs, smooth muscle cells; Ab, antibody; TNF, tumor necrosis factor; IL, interleukin; ICAM, intercellular adhesion molecule; MMP, matrix metalloproteinase; CEBP, CCAAT/enhancer binding protein; SNP, single nucleotide polymorphism; CHD, coronary heart disease; MI, myocardial infarction; ACS, acute coronary syndrome; CRP, C-reactive protein; oxLDL, oxidized low density lipoprotein; NO, nitrix oxide; iNOS, inducible nitric oxide synthase; PDGF, platelet-derived growth factor.

Importantly, human epidemiological studies support a proatherogenic role of MIF (Table 5). These studies showed a single nucleotide polymorphism (SNP) in the MIF promotor (MIF-173 CC genotype) to be a risk factor for coronary heart disease (CHD) (Herder et al., 2008) and to be more frequent in Turkish children with cardiomyopathy (Col-Araz et al., 2012). SNP rs1007888 (GG genotype) was associated with enhanced risk of myocardial infarction in female Czech patients (Tereshchenko et al., 2009). Furthermore, increased plasma levels of MIF were identified as a risk factor for increased heart failure in CHD patients with impaired glucose tolerance or type 2 diabetes mellitus (Makino et al., 2010), and were associated with inflammatory marker expression in patients with acute coronary syndrome (ACS) (Muller et al., 2012).

In conclusion, multiple animal and human studies support MIF's pro-atherosclerotic and pro-inflammatory role, and reveal MIF as an interesting target for drug development. The list of MIF inhibitors is steadily growing and includes small molecular weight or peptide drugs targeting mostly MIF's catalytic pocket or MIF trimerization (Garai and Lorand, 2009; Ouertatani-Sakouhi et al., 2010). An interesting therapeutic strategy would be to interfere with the CLF functions of MIF by blocking the interaction of MIF with its receptors. CXCR2 and CXCR4 inhibitors have recently been discussed in more detail (Liang, 2008; Stadtmann and Zarbock, 2012). However, an attractive alternative is a direct targeting of MIF instead of its receptors or devising strategies that would specifically target the MIF/CXCR interface but not other CXCR2- or CXCR4-mediated signaling effects, i.e., as stimulated by the cognate ligands CXCL8 or CXCL12, respectively. In the context of atherosclerosis, interference with MIF binding to both CXCR2 and CXCR4 by using a MIF blocking antibody interfered with MIF's pro-atherosclerotic functions (Bernhagen et al., 2007), while it would leave the protective homeostatic functions of the CXCL12-CXCR4 axis preserved (Koenen and Weber, 2010). Specific targeting of binding motifs in MIF, e.g., the pseudo-(E)LR and the N-like loop motifs critical for the MIF-CXCR2 interaction, provides an interesting strategy, but MIF motifs crucial for MIF-CXCR4 binding still remain to be identified. Finally, it is important to keep in mind that MIF exerts pleiotropic functions, and also behaves protective in different settings. For example, the MIF-CD74 axis is cardioprotective after myocardial ischemia/reperfusion injury (Miller et al., 2008; Qi et al., 2009; Luedike et al., 2012), and also exerts an important antifibrotic effect in experimental liver fibrosis (Heinrichs et al., 2011). Also, MIF polymorphisms associated with higher MIF expression were found to have a beneficial effect in community-acquired pneumonia (Yende et al., 2009). Therefore, possible negative side effects should always be carefully monitored for each new MIF inhibitor.

\section{PERICYTES COORDINATE INTERSTITIAL LEUKOCYTE MIGRATION THROUGH MIF}

MIF plays a pivotal role in leukocyte chemotaxis in the blood and other body fluids, in the arrest of leukocytes on the endothelium and their transmigration into the sub-endothelial space (Gregory et al., 2006; Bernhagen et al., 2007; Cheng et al., 2010; Santos et al., 


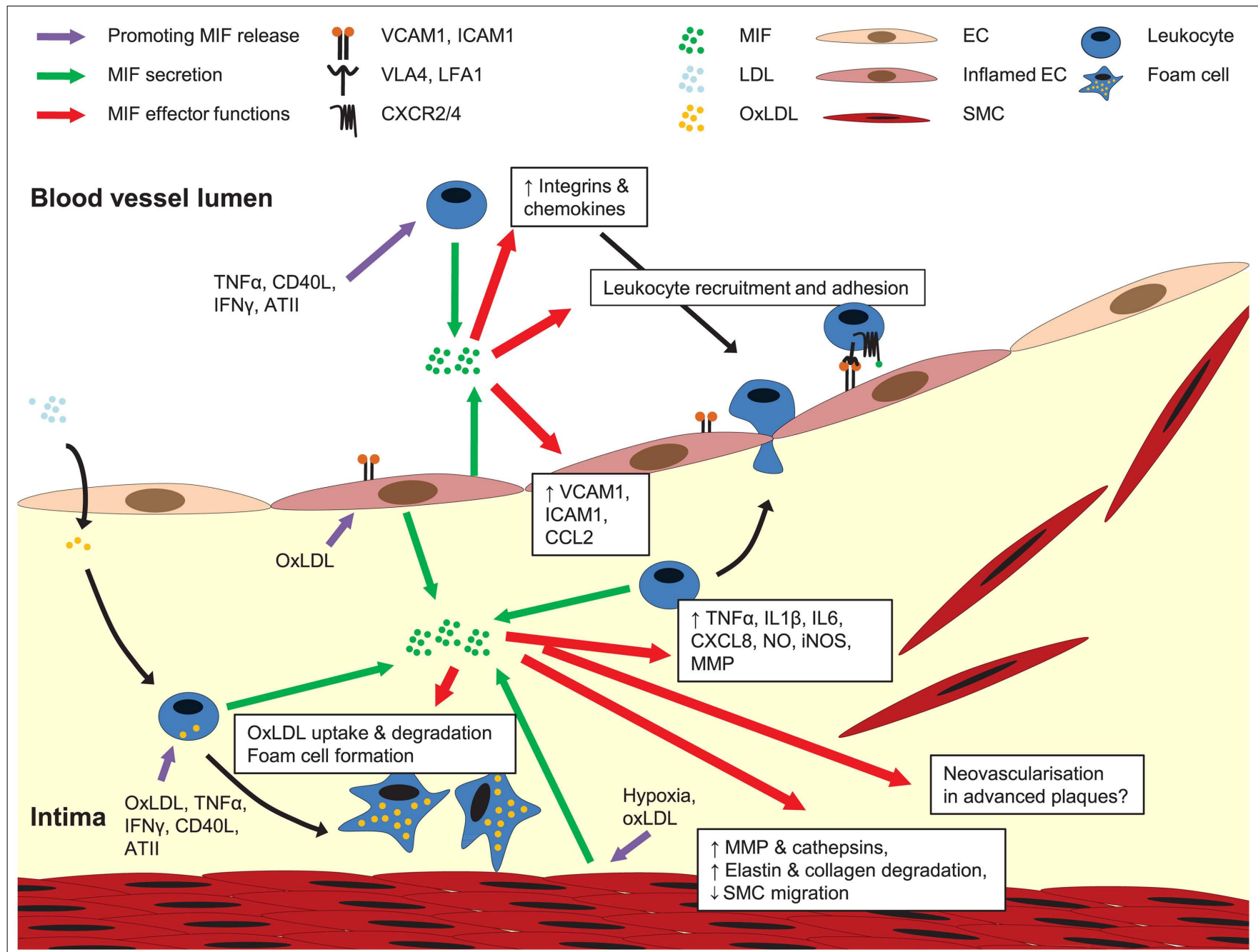

FIGURE 3 | Role of MIF in atherogenesis. MIF is secreted upon atherogenic stimulation of ECs, SMCs, and leukocytes. Once released, MIF activates leukocyte integrins, upregulates the expression of adhesion molecules and other chemokines, together mediating leukocyte recruitment and arrest on the endothelium. MIF is also implicated in pro-inflammatory cytokine expression, transdifferrentiation of macrophages to foam cells, MMP and cathepsin induction in SMCs, and regulation of SMC proliferation and migration. A potential role for MIF in neovascularization in advanced plaques remains to be investigated. For more details, see text.
2011). Intriguingly, it was recently shown that MIF also plays a role in directing extravasated leukocytes in the peri-endothelial compartment to $\mathrm{NG}_{2}{ }^{+}$pericyte-rich regions along arterioles and capillaries (Stark et al., 2013) (Box 4). Stark et al. (2013) identified NG2 ${ }^{+}$pericytes as the main source of MIF in the perivascular compartment of microvessels and demonstrated that stimulation of these cells with pro-inflammatory stimuli such as TNF, LPS, or damage-associated molecular patterns (DAMPs) released MIF and immobilized it on the cell surface of pericytes, probably through binding to CD74 and/or CXCR4. Furthermore, the release of MIF, CCL2, and CXCL8, together with the expression of ICAM1 on the pericyte surface mediated monocyte and neutrophil chemotaxis in an LFA1- and MAC1-dependent manner. As leukocyte extravasation occurs only in the postcapillary venules, which are covered by $\mathrm{NG}^{-}$pericytes, but not in arterioles and capillaries containing $\mathrm{NG}^{+}$pericytes, neutrophil and macrophage interaction with $\mathrm{NG}^{+}$pericytes can only occur after successful interstitial migration from their entry point in postcapillary venules toward capillary and arteriolar pericytes, providing interstitial migration routes for the extravasated leukocytes (Murfee et al., 2005; Stark et al., 2013). The importance of MIF in this leukocyte migration track in the pericyte sheath was stressed by the observation that subcutaneous injection of the MIF inhibitor ISO- 1 in mice reduced the number of accumulated neutrophils around $\mathrm{NG}^{+}$pericytes in the skin microvasculature without affecting their extravasation (Stark et al., 2013). This finding, together with the capacity of MIF to induce CCL2-dependent leukocyte extravasation in postcapillary venules (Gregory et al., 2006), supports the concept, that the gradual interplay of MIF with different cell types, other chemokines, or inflammatory mediators is important for successful MIF-mediated leukocyte direction from the blood vessel lumen to the site of inflammation. 


\section{Box 4 | Pericytes.}

Pericytes are also known as mural or rouget cells. They are essential components of microvessels, in which they are closely associated with the microvessel ECs, enveloped in a common basement membrane. Pericytes adhere to matrix proteins like fibrinogen, laminin, and collagen of the basement membrane through integrins. Due to their morphological and phenotypical heterogeneity, it is hard to distinguish them from other peri-endothelial cells, causing them to be often mixed up with vascular SMCs or mesenchymal cells. Also, no specific marker has been found yet. For example, pericytes covering postcapillary venules are $\mathrm{NG}^{-} \alpha \mathrm{SMA}^{+}$, whereas pericytes on arterioles and capillaries are $\mathrm{NG}_{2}{ }^{+}$. Some commonly used markers are $\alpha$-smooth muscle actin ( $\alpha \mathrm{SMA}$ ), alanyl(membrane)aminopeptidase (CD13), chondroitin sulfate proteoglycan 4 (NG2), melanoma cell adhesion molecule (CD146), platelet-derived growth factor receptor (PDGFR)- $\beta$, and desmin.

\section{CONCLUDING REMARIKS}

MIF has been recognized as an important CLF chemokine mediating leukocyte recruitment and arrest in the context of many inflammatory diseases, in particular atherosclerosis. The receptors CD74, CXCR2, and CXCR4 have been identified to bind MIF and to mediate MIF-triggered arrest functions, but the molecular mechanisms underlying MIF-mediated receptor signaling toward different cellular functions still need further refinement. For example, the molecular sequelae of MIF-triggered events leading to integrin activation on leukocytes is still largely unexplored. In addition, the composition, balance, and differential functionality of different MIF receptor complexes needs further investigation. Identification and refinement of the critical receptor binding sites of MIF could stimulate the search for drugs that specifically interfere with MIF binding to only

\section{REFERENCES}

Al-Abed, Y., Metz, C. N., Cheng, K. F., Aljabari, B., Vanpatten, S., Blau, S., et al. (2011). Thyroxine is a potential endogenous antagonist of macrophage migration inhibitory factor (MIF) activity. Proc. Natl. Acad. Sci. U.S.A. 108, 8224-8227.

Allain, F., Vanpouille, C., Carpentier, M., Slomianny, M. C., Durieux, S., and Spik, G. (2002). Interaction with glycosaminoglycans is required for cyclophilin B to trigger integrinmediated adhesion of peripheral blood T lymphocytes to extracellular matrix. Proc. Natl. Acad. Sci. U.S.A. 99, 2714-2719.

Amin, M. A., Haas, C. S., Zhu, K., Mansfield, P. J., Kim, M. J., Lackowski, N. P., et al. (2006). Migration inhibitory factor up-regulates vascular cell adhesion molecule-1 and intercellular adhesion molecule1 via Src, PI3 kinase, and NFkappaB. Blood 107, 2252-2261.

Amin, M. A., Volpert, O. V., Woods, J. M., Kumar, P., Harlow, L. A., and Koch, A. E. (2003). Migration inhibitory factor mediates angiogenesis via mitogen-activated protein kinase and phosphatidylinositol kinase. Circ. Res. 93, 321-329.

Andersson, U., Wang, H., Palmblad, K., Aveberger, A. C., Bloom, O. Erlandsson-Harris, H., et al. (2000). High mobility group 1 protein
(HMG-1) stimulates proinflammatory cytokine synthesis in human monocytes. J. Exp. Med. 192, 565-570.

Atsumi, T., Nishihira, J., Makita, Z., and Koike, T. (2000). Enhancement of oxidised low-density lipoprotein uptake by macrophages in response to macrophage migration inhibitory factor. Cytokine 12, 1553-1556.

Bacher, M., Metz, C. N., Calandra, T., Mayer, K., Chesney, J., Lohoff, M., et al. (1996). An essential regulatory role for macrophage migration inhibitory factor in T-cell activation. Proc. Natl. Acad. Sci. U.S.A. 93 , 7849-7854.

Bajetto, A., Bonavia, R., Barbero, S., and tion of chemokines and their receptors in the central nervous system: physiopathological implications. J. Neurochem. 82, 1311-1329.

Balabanian, K., Lagane, B., Infantino, S., Chow, K. Y., Harriague, J., Moepps, B., et al. (2005). The chemokine SDF-1/CXCL12 binds to and signals through the orphan receptor RDC1 in T lymphocytes. J. Biol. Chem. 280, 35760-35766.

Bernhagen, J., Calandra, T., Mitchell, R. A., Martin, S. B., Tracey, K. J., Voelter, W., et al. (1993). MIF is a pituitaryderived cytokine that potentiates lethal endotoxaemia. Nature 365, 756-759. Schettini, G. (2002). Characteriza-

one or a certain selection of MIF receptors, with the aim to selectively interfere with only a subset of MIF's pleiotropic functions.

\section{ACKNOWLEDGMENTS}

This work was supported by the Deutsche Forschungsgemeinschaft (DFG) International graduate school grant IRTG1508/1P1b (Jürgen Bernhagen), -P6 (Jürgen Bernhagen, Heidi Noels), and -P13 (Jürgen Bernhagen), by the DFG research cluster FOR809, project Be1977/4-2, to Jürgen Bernhagen, by the IZKF Aachen program of the Medical School of RWTH Aachen University (project K-05) to Jürgen Bernhagen, by the START Program of the Medical School of RWTH Aachen University to Heidi Noels, and by the German Heart Foundation/German Foundation of Heart Research to Heidi Noels.

Bernhagen, J., Krohn, R., Lue, H., Gregory, J. L., Zernecke, A., Koenen, R. R., et al. (2007). MIF is a noncognate ligand of CXC chemokine receptors in inflammatory and atherogenic cell recruitment. Nat. Med. 13 , 587-596.

Bernhagen, J., Mitchell, R. A., Calandra, T., Voelter, W., Cerami, A. and Bucala, R. (1994). Purification, bioactivity, and secondary structure analysis of mouse and human macrophage migration inhibitory factor (MIF). Biochemistry 33, 14144-14155.

Bertini, R., Howard, O. M., Dong, H. F. Oppenheim, J. J., Bizzarri, C., Sergi, R., et al. (1999). Thioredoxin, a redox enzyme released in infection and inflammation, is a unique chemoattractant for neutrophils, monocytes, and T cells. J. Exp. Med. 189, 1783-1789.

Binsky, I., Haran, M., Starlets, D. Gore, Y., Lantner, F., Harpaz, N., et al. (2007). IL-8 secreted in a macrophage migration-inhibitory factor- and CD74-dependent manner regulates $\mathrm{B}$ cell chronic lymphocytic leukemia survival. Proc. Natl. Acad. Sci. U.S.A. 104, 13408-13413.

Biragyn, A., Ruffini, P. A., Leifer, C. A., Klyushnenkova, E., Shakhov, A., Chertov, O., et al. (2002). Toll-like receptor 4-dependent activation of dendritic cells by beta-defensin 2 . Science 298, 1025-1029.

Bloom, B. R., and Bennett, B. (1966). Mechanism of a reaction in vitro associated with delayed-type hypersensitivity. Science 153, 80-82.

Boisvert, W. A., Rose, D. M., Johnson, K. A., Fuentes, M. E., Lira, S. A., Curtiss, L. K., et al. (2006). Upregulated expression of the CXCR2 ligand $\mathrm{KC} / \mathrm{GRO}$-alpha in atherosclerotic lesions plays a central role in macrophage accumulation and lesion progression. Am. J. Pathol. 168, 1385-1395.

Boisvert, W. A., Santiago, R., Curtiss, L. K., and Terkeltaub, R. A. (1998). A leukocyte homologue of the IL- 8 receptor CXCR-2 mediates the accumulation of macrophages in atherosclerotic lesions of LDL receptordeficient mice. J. Clin. Invest. 101 353-363.

Boldajipour, B., Mahabaleshwar, H., Kardash, E., ReichmanFried, M., Blaser, H., Minina, S., et al. (2008). Control of chemokine-guided cell migration by ligand sequestration. Cell 132, 463-473.

Borghese, F., and Clanchy, F. I. (2011). CD74: an emerging opportunity as a therapeutic target in cancer and autoimmune disease. Expert Opin. Ther. Targets 15, 237-251. 
Brandau, S., Jakob, M., Hemeda, H., Bruderek, K., Janeschik, S., Bootz, F., et al. (2010). Tissue-resident mesenchymal stem cells attract peripheral blood neutrophils and enhance their inflammatory activity in response to microbial challenge. J. Leukoc. Biol. 88, 1005-1015.

Bruhl, H., Cohen, C. D., Linder, S., Kretzler, M., Schlondorff, D., and Mack, M. (2003). Post-translational and cell type-specific regulation of CXCR4 expression by cytokines. Eur. J. Immunol. 33, 3028-3037.

Burger-Kentischer, A., Gobel, H., Kleemann, R., Zernecke, A., Bucala, R., Leng, L., et al. (2006). Reduction of the aortic inflammatory response in spontaneous atherosclerosis by blockade of macrophage migration inhibitory factor (MIF). Atherosclerosis $184,28-38$.

Burger-Kentischer,A., Goebel, H., Seiler, R., Fraedrich, G., Schaefer, H. E., Dimmeler, S., et al. (2002). Expression of macrophage migration inhibitory factor in different stages of human atherosclerosis. Circulation 105, 1561-1566.

Burns, J. M., Summers, B. C., Wang, Y., Melikian, A., Berahovich, R., Miao, Z., et al. (2006). A novel chemokine receptor for SDF-1 and I-TAC involved in cell survival, cell adhesion, and tumor development. J. Exp. Med. 203, 2201-2213.

Calandra, T., Bernhagen, J., Metz, C. N., Spiegel, L. A., Bacher, M., Donnelly, T., et al. (1995). MIF as a glucocorticoid-induced modulator of cytokine production. Nature 377, 68-71.

Calandra, T., Bernhagen, J., Mitchell, R. A., and Bucala, R. (1994). The macrophage is an important and previously unrecognized source of macrophage migration inhibitory factor. J. Exp. Med. 179, 1895-1902.

Calandra, T., and Roger, T. (2003). Macrophage migration inhibitory factor: a regulator of innate immunity. Nat. Rev. Immunol. 3, 791-800.

Calandra, T., Spiegel, L. A., Metz, C. N., and Bucala, R. (1998). Macrophage migration inhibitory factor is a critical mediator of the activation of immune cells by exotoxins of Grampositive bacteria. Proc. Natl. Acad. Sci. U.S.A. 95, 11383-11388.

Charo, I. F., and Ransohoff, R. M. (2006). The many roles of chemokines and chemokine receptors in inflammation. N. Engl. J. Med. 354, 610-621.

Chen, L., Yang, G., Zhang, X., Wu, J., Gu, Q., Wei, M., et al. (2009). Induction of MIF expression by oxidized LDL via activation of NF- $\mathrm{KB}$ in vascular smooth muscle cells. Atherosclerosis 207, 428-433.

Chen, Z., Sakuma, M., Zago, A. C., Zhang, X., Shi, C., Leng, L., et al. (2004). Evidence for a role of macrophage migration inhibitory factor in vascular disease. Arterioscler. Thromb. Vasc. Biol. 24, 709-714.

Cheng, Q., McKeown, S. J., Santos, L., Santiago, F. S., Khachigian, L. M., Morand, E. F., et al. (2010). Macrophage migration inhibitory factor increases leukocyte-endothelial interactions in human endothelial cells via promotion of expression of adhesion molecules. J. Immunol. 185, 1238-1247.

Chesney, J., Metz, C., Bacher, M., Peng, T., Meinhardt, A., and Bucala, R. (1999). An essential role for macrophage migration inhibitory factor (MIF) in angiogenesis and the growth of a murine lymphoma. Mol. Med. 5, 181-191.

Cho, Y., Crichlow, G. V., Vermeire, J. J., Leng, L., Du, X., Hodsdon, M. E., et al. (2010). Allosteric inhibition of macrophage migration inhibitory factor revealed by ibudilast. Proc. Natl. Acad. Sci. U.S.A. 107, 11313-11318.

Cho, Y., Jones, B. F., Vermeire, J. J., Leng, L., Difedele, L., Harrison, L. M., et al. (2007). Structural and functional characterization of a secreted hookworm Macrophage Migration Inhibitory Factor (MIF) that interacts with the human MIF receptor CD74. J. Biol. Chem. 282, 23447-23456.

Chuntharapai, A., Lee, J., Hebert, C. A., and Kim, K. J. (1994). Monoclonal antibodies detect different distribution patterns of IL-8 receptor A and IL-8 receptor B on human peripheral blood leukocytes. J. Immunol. 153, 5682-5688.

Clark-Lewis, I., Kim, K. S., Rajarathnam, K., Gong, J. H., Dewald, B., Moser, B., et al. (1995). Structure-activity relationships of chemokines. J. Leukoc. Biol. 57, 703-711.

Clore, G. M., Appella, E., Yamada, M., Matsushima, K., and Gronenborn, A. M. (1990). Three-dimensional structure of interleukin 8 in solution. Biochemistry 29, 1689-1696.

Col-Araz, N., Oguzkan-Balci, S., Baspinar, O., Sever, T., Balat, A., and Pehlivan, S. (2012). Mannose binding lectin and macrophage migration inhibitory factor gene polymorphisms in Turkish children with cardiomyopathy: no association with MBL2 codon 54 $\mathrm{A} / \mathrm{B}$ genotype, but an association between MIF -173 CC genotype. Int. J. Med. Sci. 9, 506-512.

Colley, N. J., Baker, E. K., Stamnes, M. A., and Zuker, C. S. (1991). The cyclophilin homolog ninaA is required in the secretory pathway. Cell 67, 255-263.

Contento, R. L., Molon, B., Boularan, C., Pozzan, T., Manes, S., Marullo, S., et al. (2008). CXCR4-CCR5: a couple modulating $\mathrm{T}$ cell functions. Proc. Natl. Acad. Sci. U.S.A. 105, 10101-10106

Dambly-Chaudiere, C., Cubedo, N., and Ghysen, A. (2007). Control of cell migration in the development of the posterior lateral line: antagonistic interactions between the chemokine receptors CXCR4 and CXCR7/RDC1. BMC Dev. Biol. 7:23. doi:10.1186/1471-213X-7-23

David, J. R. (1966). Delayed hypersensitivity in vitro: its mediation by cell-free substances formed by lymphoid cell-antigen interaction. Proc. Natl. Acad. Sci. U.S.A. 56, 72-77.

Degryse, B., and de Virgilio, M. (2003). The nuclear protein HMGB1, a new kind of chemokine? FEBS Lett. 553 , 11-17.

Dessein, A. F., Stechly, L., Jonckheere, N., Dumont, P., Monte, D., Leteurtre, E. et al. (2010). Autocrine induction of invasive and metastatic phenotypes by the MIF-CXCR4 axis in drugresistant human colon cancer cells. Cancer Res. 70, 4644-4654.

Donn, R. P., Shelley, E., Ollier, W. E., and Thomson, W. (2001). A novel 5'-flanking region polymorphism of macrophage migration inhibitory factor is associated with systemiconset juvenile idiopathic arthritis. Arthritis Rheum. 44, 1782-1785.

El-Turk, F., Cascella, M., OuertataniSakouhi, H., Narayanan, R. L., Leng, L., Bucala, R., et al. (2008). The conformational flexibility of the carboxy terminal residues $105-114$ is a key modulator of the catalytic activity and stability of macrophage migration inhibitory factor. Biochemistry 47, 10740-10756.

El-Turk, F., Fauvet, B., Ashrafi, A., Ouertatani-Sakouhi, H., Cho, M. K., Neri, M., et al. (2012). Characterization of molecular determinants of the conformational stability of macrophage migration inhibitory factor: leucine 46 hydrophobic pocket. PLOS ONE 7:e45024. doi:10.1371/journal.pone.0045024

Fan, H., Hall, P., Santos, L. L., Gregory, J. L., Fingerle-Rowson, G., Bucala, R. et al. (2011). Macrophage migration inhibitory factor and CD74 regulate macrophage chemotactic responses via MAPK and Rho GTPase. J. Immunol. 186, 4915-4924.

Fernandez, E. J., and Lolis, E. (2002). Structure, function, and inhibition of chemokines. Annu. Rev. Pharmacol. Toxicol. 42, 469-499.

Fingerle-Rowson, G., Kaleswarapu, D. R., Schlander, C., Kabgani, N., Brocks, T., Reinart, N., et al. (2009). A tautomerase-null macrophage migration-inhibitory factor (MIF) gene knock-in mouse model reveals that protein interactions and not enzymatic activity mediate MIFdependent growth regulation. Mol. Cell. Biol. 29, 1922-1932.

Fiuza, C., Bustin, M., Talwar, S., Tropea, M., Gerstenberger, E., Shelhamer, J. H., et al. (2003). Inflammationpromoting activity of HMGB1 on human microvascular endothelial cells. Blood 101, 2652-2660.

Flieger, O., Engling, A., Bucala, R., Lue, H., Nickel, W., and Bernhagen, J. (2003). Regulated secretion of macrophage migration inhibitory factor is mediated by a non-classical pathway involving an ABC transporter. FEBS Lett. 551, 78-86.

Frye, B. C., Halfter, S., Djudjaj, S., Muehlenberg, P., Weber, S., Raffetseder, U., et al. (2009). Ybox protein-1 is actively secreted through a non-classical pathway and acts as an extracellular mitogen. EMBO Rep. 10, 783-789.

Gao, H., Neff, T. A., Guo, R. F., Speyer, C. L., Sarma, J. V., Tomlins, S., et al. (2005). Evidence for a functional role of the second C5a receptor C5L2. FASEB J. 19, 1003-1005.

Garai, J., and Lorand, T. (2009). Macrophage migration inhibitory factor (MIF) tautomerase inhibitors as potential novel anti-inflammatory agents: current developments. Curr. Med. Chem. 16, 1091-1114.

Gordin, M., Tesio, M., Cohen, S., Gore, Y., Lantner, F., Leng, L., et al. (2010). c-Met and its ligand hepatocyte growth factor/scatter factor regulate mature $B$ cell survival in a pathway induced by CD74. J. Immunol. 185, 2020-2031.

Gore, Y., Starlets, D., Maharshak, N., Becker-Herman, S., Kaneyuki, U. Leng, L., et al. (2008). Macrophage migration inhibitory factor induces $\mathrm{B}$ cell survival by activation of a CD74-CD44 receptor complex. J. Biol. Chem. 283, 2784-2792.

Govindaraju, V., Michoud, M. C., AlChalabi, M., Ferraro, P., Powell, W. S., and Martin, J. G. (2006). Interleukin-8: novel roles in human 
airway smooth muscle cell contraction and migration. Am. J. Physiol. Cell Physiol. 291, C957-965.

Gregory, J. L., Hall, P., Leech, M., Morand, E. F., and Hickey, M. J. (2009). Independent roles of macrophage migration inhibitory factor and endogenous, but not exogenous glucocorticoids in regulating leukocyte trafficking. Microcirculation 16, 735-748.

Gregory, J. L., Leech, M. T., David, J. R., Yang, Y. H., Dacumos, A., and Hickey, M. J. (2004). Reduced leukocyte-endothelial cell interactions in the inflamed microcirculation of macrophage migration inhibitory factor-deficient mice. Arthritis Rheum. 50, 3023-3034.

Gregory, J. L., Morand, E. F., McKeown, S. J., Ralph, J. A., Hall, P., Yang, Y. H., et al. (2006). Macrophage migration inhibitory factor induces macrophage recruitment via CC chemokine ligand 2. J. Immunol. 177, 8072-8079.

Gupta, S. K., Lysko, P. G., Pillarisetti, K., Ohlstein, E., and Stadel, J. M. (1998). Chemokine receptors in human endothelial cells. Functional expression of CXCR4 and its transcriptional regulation by inflammatory cytokines. J. Biol. Chem. 273, 4282-4287.

Hamatake, M., Aoki, T., Futahashi, Y., Urano, E., Yamamoto, N., and Komano, J. (2009). Ligand-independent higher-order multimerization of CXCR4, a G-protein-coupled chemokine receptor involved in targeted metastasis. Cancer Sci. 100, 95-102.

Hattermann, K., Held-Feindt, J., Lucius, R., Muerkoster, S. S., Penfold, M. E., Schall, T. J., et al. (2010). The chemokine receptor CXCR7 is highly expressed in human glioma cells and mediates antiapoptotic effects. Cancer Res. 70, 3299-3308.

Hebert, C. A., Vitangcol, R. V., and Baker, J. B. (1991). Scanning mutagenesis of interleukin-8 identifies a cluster of residues required for receptor binding. J. Biol. Chem. 266, 18989-18994.

Heinrichs, D., Knauel, M., Offermanns, C., Berres, M. L., Nellen, A., Leng, L., et al. (2011). Macrophage migration inhibitory factor (MIF) exerts antifibrotic effects in experimental liver fibrosis via CD74. Proc. Natl. Acad. Sci. U.S.A. 108, 17444-17449.

Herder, C., Illig, T., Baumert, J., Muller, M., Klopp, N., Khuseyinova, N., et al. (2008). Macrophage migration inhibitory factor (MIF) and risk for coronary heart disease: results from the MONICA/KORA Augsburg case-cohort study, 1984-2002. Atherosclerosis 200, 380-388.

Hermanowski-Vosatka, A., Mundt, S. S., Ayala, J. M., Goyal, S., Hanlon, W. A., Czerwinski, R. M., et al. (1999). Enzymatically inactive macrophage migration inhibitory factor inhibits monocyte chemotaxis and random migration. Biochemistry 38, 12841-12849.

Hoover, D. M., Boulegue, C., Yang, D., Oppenheim, J. J., Tucker, K., Lu, W. et al. (2002). The structure of human macrophage inflammatory protein3alpha/CCL20. Linking antimicrobial and CC chemokine receptor6-binding activities with human beta-defensins. J. Biol. Chem. 277, 37647-37654.

Infantino, S., Moepps, B., and Thelen, M. (2006). Expression and regulation of the orphan receptor RDC1 and its putative ligand in human dendritic and B cells. J. Immunol. 176, 2197-2207.

Ingersoll, M. A., Spanbroek, R., Lottaz, C., Gautier, E. L., Frankenberger, M., Hoffmann, R., et al. (2010). Comparison of gene expression profiles between human and mouse monocyte subsets. Blood 115, e10-e19.

Jung, H., Seong, H. A., and $\mathrm{Ha}, \mathrm{H}$. (2008). Critical role of cysteine residue 81 of macrophage migration inhibitory factor (MIF) in MIFinduced inhibition of p53 activity. J. Biol. Chem. 283, 20383-20396.

Kerschbaumer, R. J., Rieger, M., Volkel, D., Le Roy, D., Roger, T., Garbaraviciene, J., et al. (2012). Neutralization of macrophage migration inhibitory factor (MIF) by fully human antibodies correlates with their specificity for the beta-sheet structure of MIF. J. Biol. Chem. 287, 7446-7455.

Khromykh, L. M., Kulikova, N. L., Anfalova, T. V., Muranova, T. A., Abramov, V. M., Vasiliev, A. M., et al. (2007). Cyclophilin A produced by thymocytes regulates the migration of murine bone marrow cells. Cell. Immunol. 249, 46-53.

Kim, S., Miska, K. B., Jenkins, M. C., Fetterer, R. H., Cox, C. M., Stuard, L. H., et al. (2010). Molecular cloning and functional characterization of the avian macrophage migration inhibitory factor (MIF). Dev. Comp. Immunol. 34, 1021-1032.

Kitani, A., Nakashima, N., Izumihara, T., Inagaki, M., Baoui, X., Yu, S., et al. (1998). Soluble VCAM-1 induces chemotaxis of Jurkat and synovial fluid $\mathrm{T}$ cells bearing high affinity very late antigen-4. J. Immunol. 161, 4931-4938.
Kleemann, R., Hausser, A., Geiger, G. Mischke, R., Burger-Kentischer, A., Flieger, O., et al. (2000). Intracellular action of the cytokine MIF to modulate AP-1 activity and the cell cycle through Jab1. Nature 408, 211-216.

Kleemann, R., Kapurniotu, A., Frank, R. W., Gessner, A., Mischke, R., Flieger, O., et al. (1998). Disulfide analysis reveals a role for macrophage migration inhibitory factor (MIF) as thiolprotein oxidoreductase. J. Mol. Biol. 280, 85-102.

Kleemann, R., Kapurniotu, A., Mischke, R., Held, J., and Bernhagen, J. (1999). Characterization of catalytic centre mutants of macrophage migration inhibitory factor (MIF) and comparison to Cys81Ser MIF. Eur. J. Biochem. 261, 753-766.

Koenen, R. R., and Weber, C. (2010) Therapeutic targeting of chemokine interactions in atherosclerosis. Nat. Rev. Drug Discov. 9, 141-153.

Kong, Y. Z., Huang, X. R., Ouyang, X., Tan, J. J., Fingerle-Rowson, G., Bacher, M., et al. (2005a). Evidence for vascular macrophage migration inhibitory factor in destabilization of human atherosclerotic plaques. Cardiovasc. Res. 65, 272-282.

Kong, Y. Z., Yu, X., Tang, J. J., Ouyang, X., Huang, X. R., Fingerle-Rowson, G., et al. (2005b). Macrophage migration inhibitory factor induces MMP-9 expression: implications for destabilization of human atherosclerotic plaques. Atherosclerosis 178, 207-215.

Kraemer, S., Lue, H., Zernecke, A. Kapurniotu, A., Andreetto, E., Frank, R., et al. (2011). MIF-chemokine receptor interactions in atherogenesis are dependent on an N-loopbased 2-site binding mechanism. FASEB J. 25, 894-906.

Kraemer, S., Rajabi, S. A., El Bounkari, O., and Bernhagen, J. (2013). Hetero-oligomerization of chemokine receptors: diversity and relevance for function. Curr. Med. Chem. [Epub ahead of print].

Kraemer, S., Weber, C., and Bernhagen, J. (2012). "MIF and the chemokine axis," in The MIF Handbook, Chap. I-2, ed. R. Bucala (Singapore: World Scientific Publishing), 23-53.

Kumar, R., Tripathi, V., Ahmad, M. Nath, N., Mir, R. A., Chauhan, S. S., et al. (2012). CXCR7 mediated Gialpha independent activation of ERK and Akt promotes cell survival and chemotaxis in T cells. Cell. Immunol. 272, 230-241.

Lan, H. Y., Bacher, M., Yang, N., Mu, W., Nikolic-Paterson, D. J., Metz, C., et al. (1997). The pathogenic role of macrophage migration inhibitory factor in immunologically induced kidney disease in the rat. J. Exp. Med. 185, 1455-1465.

Lee, C. Y., Su, M. J., Huang, C. Y., Chen, M. Y., Hsu, H. C., Lin, C. Y., et al. (2012). Macrophage migration inhibitory factor increases cell motility and up-regulates alphavbeta3 integrin in human chondrosarcoma cells. J. Cell. Biochem. 113, 1590-1598.

Lefort, C. T., and Ley, K. (2012). Neutrophil arrest by LFA-1 activation. Front. Immunol. 3:157. doi:10.3389/fimmu.2012.00157

Leng, L., Metz, C. N., Fang, Y., Xu, J., Donnelly, S., Baugh, J., et al. (2003). MIF signal transduction initiated by binding to CD74. J. Exp. Med. 197, 1467-1476.

Levoye, A., Balabanian, K., Baleux, F., Bachelerie, F., and Lagane, B. (2009). CXCR7 heterodimerizes with CXCR4 and regulates CXCL12mediated $\mathrm{G}$ protein signaling. Blood 113, 6085-6093.

Ley, K., Laudanna, C., Cybulsky, M. I., and Nourshargh, S. (2007). Getting to the site of inflammation: the leukocyte adhesion cascade updated. Nat. Rev. Immunol. 7, 678-689.

Liang, X. (2008). CXCR4, inhibitors and mechanisms of action. Chem. Biol. Drug Des. 72, 97-110.

Lin, S. G., Yu, X. Y., Chen, Y. X., Huang, X. R., Metz, C., Bucala, R., et al. (2000). De novo expression of macrophage migration inhibitory factor in atherogenesis in rabbits. Circ. Res. 87, 1202-1208.

Liu, L., Chen, J., Ji, C., Zhang, J., Sun, J., Li, Y., et al. (2008). Macrophage migration inhibitory factor (MIF) interacts with Bim and inhibits Bimmediated apoptosis. Mol. Cells 26, 193-199.

Lue, H., Dewor, M., Leng, L., Bucala, R., and Bernhagen, J. (2011). Activation of the JNK signalling pathway by macrophage migration inhibitory factor (MIF) and dependence on CXCR4 and CD74. Cell. Signal. 23, 135-144.

Lue, H., Kapurniotu, A., FingerleRowson, G., Roger, T., Leng, L., Thiele, M., et al. (2006). Rapid and transient activation of the ERK MAPK signalling pathway by macrophage migration inhibitory factor (MIF) and dependence on JAB1/CSN5 and Src kinase activity. Cell. Signal. 18, 688-703.

Lue, H., Thiele, M., Franz, J., Dahl, E. Speckgens, S., Leng, L., et al. (2007). Macrophage migration inhibitory factor (MIF) promotes cell survival by activation of the Akt pathway and role for CSN5/JAB1 in the control of 
autocrine MIF activity. Oncogene 26, 5046-5059.

Luedike, P., Hendgen-Cotta, U. B., Sobierajski, J., Totzeck, M., Reeh, M., Dewor, M., et al. (2012). Cardioprotection through S-nitros(yl)ation of macrophage migration inhibitory factor. Circulation 125, 1880-1889.

Luker, K. E., Gupta, M., and Luker, G. D. (2009). Imaging chemokine receptor dimerization with firefly luciferase complementation. FASEB J. 23, 823-834.

Ma, Q., Jones, D., Borghesani, P. R., Segal, R. A., Nagasawa, T., Kishimoto, T., et al. (1998). Impaired B-lymphopoiesis, myelopoiesis, and derailed cerebellar neuron migration in CXCR4- and SDF-1-deficient mice. Proc. Natl. Acad. Sci. U.S.A. 95, 9448-9453.

Makino, A., Nakamura, T., Hirano, M., Kitta, Y., Sano, K., Kobayashi, T., et al. (2010). High plasma levels of macrophage migration inhibitory factor are associated with adverse long-term outcome in patients with stable coronary artery disease and impaired glucose tolerance or type 2 diabetes mellitus. Atherosclerosis 213, 573-578.

Martin-Ventura, J. L., Madrigal-Matute, J., Munoz-Garcia, B., Blanco-Colio, L. M., Van Oostrom, M., Zalba, G., et al. (2009). Increased CD74 expression in human atherosclerotic plaques: contribution to inflammatory responses in vascular cells. Cardiovasc. Res. 83, 586-594.

Merk, M., Mitchell, R. A., Endres, S., and Bucala, R. (2012). D-dopachrome tautomerase (D-DT or MIF-2): doubling the MIF cytokine family. Cytokine 59, 10-17.

Miller, E. J., Li, J., Leng, L., McDonald, C., Atsumi, T., Bucala, R., et al. (2008). Macrophage migration inhibitory factor stimulates AMP-activated protein kinase in the ischaemic heart. Nature 451, 578-582.

Milligan, G. (2007). G protein-coupled receptor dimerisation: molecular basis and relevance to function. Biochim. Biophys. Acta 1768, 825-835.

Mischke, R., Kleemann, R., Brunner, H., and Bernhagen, J. (1998). Cross-linking and mutational analysis of the oligomerization state of the cytokine macrophage migration inhibitory factor (MIF). FEBS Lett. 427, 85-90.

Mitchell, R. A., Liao, H., Chesney, J., Fingerle-Rowson, G., Baugh, J., David, J., et al. (2002). Macrophage migration inhibitory factor (MIF) sustains macrophage proinflammatory function by inhibiting p53: regulatory role in the innate immune response. Proc. Natl. Acad. Sci. U.S.A. 99, 345-350.

Mitchell, R. A., Metz, C. N., Peng, T., and Bucala, R. (1999). Sustained mitogen-activated protein kinase (MAPK) and cytoplasmic phospholipase A2 activation by macrophage migration inhibitory factor (MIF). Regulatory role in cell proliferation and glucocorticoid action. J. Biol. Chem. 274, 18100-18106.

Mohle, R., Bautz, F., Rafii, S., Moore, M. A., Brugger, W., and Kanz, L. (1998). The chemokine receptor CXCR-4 is expressed on CD34+ hematopoietic progenitors and leukemic cells and mediates transendothelial migration induced by stromal cell-derived factor-1. Blood 91, 4523-4530.

Montresor, A., Toffali, L., Constantin, G., and Laudanna, C. (2012). Chemokines and the signaling modules regulating integrin affinity. Front. Immunol. 3:127. doi:10.3389/fimmu.2012.00127

Morand, E. F., Leech, M., and Bernhagen, J. (2006). MIF: a new cytokine link between rheumatoid arthritis and atherosclerosis. Nat. Rev. Drug Discov. 5, 399-410.

Muller, I. I., Muller, K. A., Schonleber, H., Karathanos, A., Schneider, M., Jorbenadze, R., et al. (2012). Macrophage migration inhibitory factor is enhanced in acute coronary syndromes and is associated with the inflammatory response. PLOS ONE 7:e38376. doi:10.1371/journal.pone.0038376

Murdoch, C., Monk, P. N., and Finn, A. (1999). Cxc chemokine receptor expression on human endothelial cells. Cytokine 11, 704-712.

Murfee, W. L., Skalak, T. C., and Peirce, S. M. (2005). Differential arter$\mathrm{ial} /$ venous expression of NG2 proteoglycan in perivascular cells along microvessels: identifying a venulespecific phenotype. Microcirculation 12, 151-160.

Murphy, P. M., Baggiolini, M., Charo, I. F., Hebert, C. A., Horuk, R., Matsushima, K., et al. (2000). International union of pharmacology. XXII. Nomenclature for chemokine receptors. Pharmacol. Rev. 52, 145-176.

Neel, N. F., Barzik, M., Raman, D., Sobolik-Delmaire, T., Sai, J., Ham, A. J., et al. (2009). VASP is a CXCR2-interacting protein that regulates CXCR2-mediated polarization and chemotaxis. J. Cell Sci. 122, 1882-1894.

Neel, N. F., Sai, J., Ham, A. J., SobolikDelmaire, T., Mernaugh, R. L., and Richmond, A. (2011) IQGAP1 is a novel CXCR2interacting protein and essential component of the "chemosynapse.” PLoS ONE 6:e23813. doi:10.1371/journal.pone.0023813

Nguyen, M. T., Beck, J., Lue, H., Funfzig, H., Kleemann, R., Koolwijk, P., et al. (2003). A 16-residue peptide fragment of macrophage migration inhibitory factor. J. Biol. Chem. 278, 33654-33671.

Nie, Y., Waite, J., Brewer, F., Sunshine, M. J., Littman, D. R., and Zou, Y. R. (2004). The role of CXCR4 in maintaining peripheral B cell compartments and humoral immunity. J. Exp. Med. 200, 1145-1156.

Nishihira, J., Koyama, Y., and Mizue, Y. (1998). Identification of macrophage migration inhibitory factor (MIF) in human vascular endothelial cells and its induction by lipopolysaccharide. Cytokine 10, 199-205.

Noels, H., Bernhagen, J., and Weber, C. (2009). Macrophage migration inhibitory factor: a noncanonical chemokine important in atherosclerosis. Trends Cardiovasc. Med. 19, 76-86.

Noels, H., Bernhagen, J., and Weber, C. (2012). "MIF in atherosclerosis," in MIF: Most Interesting Factor Revisited, Chap. V-1, ed. R. Bucala (Singapore: World Scientific Publishing), 321-358.

Ogawa, H., Nishihira, J., Sato, Y., Kondo, M., Takahashi, N., Oshima, T., et al. (2000). An antibody for macrophage migration inhibitory factor suppresses tumour growth and inhibits tumour-associated angiogenesis. Cytokine 12, 309-314.

Oppenheim, J. J., Biragyn, A., Kwak, L. W., and Yang, D. (2003). Roles of antimicrobial peptides such as defensins in innate and adaptive immunity. Ann. Rheum. Dis. 62(Suppl. 2), ii17-21.

Oppenheim, J. J., and Yang, D. (2005). Alarmins: chemotactic activators of immune responses. Curr. Opin. Immunol. 17, 359-365.

Orita, M., Yamamoto, S., Katayama, N., Aoki, M., Takayama, K., Yamagiwa, Y., et al. (2001). Coumarin and chromen-4-one analogues as tautomerase inhibitors of macrophage migration inhibitory factor: discovery and X-ray crystallography. $J$. Med. Chem. 44, 540-547.

Ouertatani-Sakouhi, H., El-Turk, F., Fauvet, B., Cho, M. K., Pinar Karpinar, D., Le Roy, D., et al. (2010). Identification and characterization of novel classes of macrophage migration inhibitory factor (MIF) inhibitors with distinct mechanisms of action. J. Biol. Chem. 285, 26581-26598.

Palomino-Morales, R., GonzalezJuanatey, C., Vazquez-Rodriguez, T. R., Torres, O., Miranda-Filloy, J. A., Llorca, J., et al. (2010). Lack of association between macrophage migration inhibitory factor-173 gene polymorphism with disease susceptibility and cardiovascular risk in rheumatoid arthritis patients from northwestern Spain. Clin. Exp. Rheumatol. 28, 68-72.

Pan, J. H., Sukhova, G. K., Yang, J. T. Wang, B., Xie, T., Fu, H., et al. (2004) Macrophage migration inhibitory factor deficiency impairs atherosclerosis in low-density lipoprotein receptor-deficient mice. Circulation 109, 3149-3153.

Parenty, G., Appelbe, S., and Milligan, G. (2008). CXCR2 chemokine receptor antagonism enhances DOP opioid receptor function via allosteric regulation of the CXCR2-DOP receptor heterodimer. Biochem. J. 412, 245-256.

Philo, J. S., Yang, T. H., and Labarre, M. (2004). Re-examining the oligomerization state of macrophage migration inhibitory factor (MIF) in solution. Biophys. Chem. 108, 77-87.

Price, E. R., Jin, M., Lim, D., Pati, S., Walsh, C. T., and McKeon, F. D. (1994). Cyclophilin B trafficking through the secretory pathway is altered by binding of cyclosporin A. Proc. Natl. Acad. Sci. U.S.A. 91, 3931-3935.

Pullerits, R., Jonsson, I. M., Verdrengh, M., Bokarewa, M., Andersson, U., Erlandsson-Harris, H., et al. (2003). High mobility group box chromosomal protein 1, a DNA binding cytokine, induces arthritis. Arthritis Rheum. 48, 1693-1700.

Qi, D., Hu, X., Wu, X., Merk, M., Leng, L., Bucala, R., et al. (2009). Cardiac macrophage migration inhibitory factor inhibits JNK pathway activation and injury during ischemia/reperfusion. J. Clin. Invest. 119, 3807-3816.

Quax, P. H. A., Boxman, I. L. A., van Kesteren, J. H., Verheijen, J. H., and Ponec, M. (1994). Plasminogen activators are involved in keratinocyte and fibroblast migration in wounded cultures in vitro. Fibrinolysis 8, 221-228.

Rajagopal, S., Kim, J., Ahn, S., Craig, S., Lam, C. M., Gerard, N. P., et al. (2010). Beta-arrestin- but not G protein-mediated signaling by the “decoy" receptor CXCR7. Proc. Natl. Acad. Sci. U.S.A. 107, 628-632. 
Rajagopalan, L., and Rajarathnam, K. (2006). Structural basis of chemokine receptor function - a model for binding affinity and ligand selectivity. Biosci. Rep. 26, 325-339.

Rauen, T., Raffetseder, U., Frye, B. C., Djudjaj, S., Muhlenberg, P. J., Eitner, F., et al. (2009). YB-1 acts as a ligand for Notch-3 receptors and modulates receptor activation. J. Biol. Chem. 284, 26928-26940.

Reidy, T., Rittenberg, A., Dwyer, M., D'Ortona, S., Pier, G., and Gadjeva, M. (2013). Homotrimeric MIF drives inflammatory responses in the corneal epithelium by promoting caveolin-rich platform assembly in response to infection. J. Biol. Chem. 288, 8269-8278.

Reinart, N., Nguyen, P. H., Boucas, J., Rosen, N., Kvasnicka, H. M., Heukamp, L., et al. (2013). Delayed developent of chronic lymphocytic leukemia in the absence of macrophage migration inhibitory factor. Blood 121, 812-821.

Ren, Y., Tsui, H. T., Poon, R. T., Ng, I. O., Li, Z., Chen, Y., et al. (2003). Macrophage migration inhibitory factor: roles in regulating tumor cell migration and expression of angiogenic factors in hepatocellular carcinoma. Int. J. Cancer 107, 22-29.

Resnati, M., Pallavicini, I., Wang, J. M., Oppenheim, J., Serhan, C. N., Romano, M., et al. (2002). The fibrinolytic receptor for urokinase activates the $\mathrm{G}$ proteincoupled chemotactic receptor FPRL1/LXA4R. Proc. Natl. Acad. Sci. U.S.A. 99, 1359-1364.

Riedemann, E., Rojas, C., and Quevedo, I. (2004). Somatotropic pituitary tumor in a patient with a previous ovarian strumal carcinoid. Report of one case. Rev. Med. Chil. 132, 857-859.

Roovers, K., and Assoian, R. K. (2003). Effects of rho kinase and actin stress fibers on sustained extracellular signal-regulated kinase activity and activation of $\mathrm{G}(1)$ phase cyclindependent kinases. Mol. Cell. Biol. 23, 4283-4294.

Rosengren, E., Aman, P., Thelin, S., Hansson, C., Ahlfors, S., Bjork, P., et al. (1997). The macrophage migration inhibitory factor MIF is a phenylpyruvate tautomerase. FEBS Lett. 417, 85-88.

Roychoudhury, P. K., Khaparde, S. S., Mattiasson, B., and Kumar, A. (2006). Synthesis, regulation and production of urokinase using mammalian cell culture: a comprehensive review. Biotechnol. Adv. 24, 514-528.
Saini, V., Marchese, A., and Majetschak, M. (2010). CXC chemokine receptor 4 is a cell surface receptor for extracellular ubiquitin. J. Biol. Chem. 285, 15566-15576.

Sainz, J., and Sata, M. (2007). CXCR4, a key modulator of vascular progenitor cells. Arterioscler. Thromb. Vasc. Biol. 27, 263-265.

Santos, L. L., Fan, H., Hall, P., Ngo, D., Mackay, C. R., Fingerle-Rowson, G., et al. (2011). Macrophage migration inhibitory factor regulates neutrophil chemotactic responses in inflammatory arthritis in mice. Arthritis Rheum. 63, 960-970.

Schecter, A. D., Berman, A. B., Yi, L., Mosoian, A., McManus, C. M., Berman, J. W., et al. (2001). HIV envelope gp120 activates human arterial smooth muscle cells. Proc. Natl. Acad. Sci. U.S.A. 98, 10142-10147.

Schiraldi, M., Raucci, A., Munoz, L. M., Livoti, E., Celona, B., Venereau, E., et al. (2012). HMGB1 promotes recruitment of inflammatory cells to damaged tissues by forming a complex with CXCL12 and signaling via CXCR4. J. Exp. Med. 209, 551-563.

Schmeisser, A., Marquetant, R., Illmer, T., Graffy, C., Garlichs, C. D. Bockler, D., et al. (2005). The expression of macrophage migration inhibitory factor lalpha (MIF 1alpha) in human atherosclerotic plaques is induced by different proatherogenic stimuli and associated with plaque instability. Atherosclerosis 178, 83-94.

Schober, A., Bernhagen, J., Thiele, M., Zeiffer, U., Knarren, S., Roller, M., et al. (2004). Stabilization of atherosclerotic plaques by blockade of macrophage migration inhibitory factor after vascular injury in apolipoprotein E-deficient mice. Circulation 109, 380-385.

Schrans-Stassen, B. H., Lue, H., Sonnemans, D. G., Bernhagen, J., and Post, M. J. (2005). Stimulation of vascular smooth muscle cell migration by macrophage migration inhibitory factor. Antioxid. Redox Signal. 7, 1211-1216.

Schwartz, V., Lue, H., Kraemer, S., Korbiel, J., Krohn, R., Ohl, K., et al. (2009). A functional heteromeric MIF receptor formed by CD74 and CXCR4. FEBS Lett. 583, 2749-2757.

Schwertassek, U., Balmer, Y., Gutscher, M., Weingarten, L., Preuss, M. Engelhard, J., et al. (2007). Selective redox regulation of cytokine receptor signaling by extracellular thioredoxin-1. EMBO J. 26, 3086-3097.
Shi, X., Leng, L., Wang, T., Wang, W., Du, X., Li, J., et al. (2006). CD44 is the signaling component of the macrophage migration inhibitory factor-CD74 receptor complex. Immunity 25, 595-606.

Shimizu, S., Brown, M., Sengupta, R., Penfold, M. E., and Meucci, O. (2011). CXCR7 protein expression in human adult brain and differentiated neurons. PLoS ONE 6:e20680. doi:10.1371/journal.pone.0020680

Shimizu, T., Nishihira, J., Watanabe, $\mathrm{H}$. Abe, R., Honda, A., Ishibashi, T. et al. (2004). Macrophage migration inhibitory factor is induced by thrombin and factor $\mathrm{Xa}$ in endothelial cells. J. Biol. Chem. 279, 13729-13737.

Simons, D., Grieb, G., Hristov, M. Pallua, N., Weber, C., Bernhagen, J., et al. (2011). Hypoxia-induced endothelial secretion of macrophage migration inhibitory factor and role in endothelial progenitor cell recruitment. J. Cell. Mol. Med. 15, 668-678.

Smith, D. F., Deem, T. L., Bruce, A. C., Reutershan, J., Wu, D., and Ley, K. (2006). Leukocyte phosphoinositide-3 kinase \{gamma\} is required for chemokineinduced, sustained adhesion under flow in vivo. J. Leukoc. Biol. 80 1491-1499.

Soehnlein, O., Wantha, S., Simsekyilmaz, S., Doring, Y., Megens, R. T., Mause, S. F., et al. (2011). Neutrophil-derived cathelicidin protects from neointimal hyperplasia. Sci. Transl. Med. 3 , 103 ra198.

Sozzani, S., Sallusto, F., Luini, W., Zhou, D., Piemonti, L., Allavena, P., et al. (1995). Migration of dendritic cells in response to formyl peptides, $\mathrm{C} 5 \mathrm{a}$, and a distinct set of chemokines. $J$. Immunol. 155, 3292-3295.

Stadtmann, A., and Zarbock, A. (2012). CXCR2: from bench to bedside. Front. Immunol. 3:263. doi:10.3389/fimmu.2012.00263

Stark, K., Eckart, A., Haidari, S., Tirniceriu, A., Lorenz, M., Von Bruhl, M. L., et al. (2013). Capillary and arteriolar pericytes attract innate leukocytes exiting through venules and "instruct" them with patternrecognition and motility programs. Nat. Immunol. 14, 41-51.

Stein, R., Mattes, M. J., Cardillo, T. M., Hansen, H. J., Chang, C. H., Burton, J., et al. (2007). CD74: a new candidate target for the immunotherapy of B-cell neoplasms. Clin. Cancer Res. 13, 5556s-5563s.

Sugimoto, H., Suzuki, M., Nakagawa, A., Tanaka, I., and Nishihira, J. (1996).
Crystal structure of macrophage migration inhibitory factor from human lymphocyte at 2.1 A resolution. FEBS Lett. 389, 145-148.

Sugimoto, H., Taniguchi, M., Nakagawa, A., Tanaka, I., Suzuki, M., and Nishihira, J. (1999). Crystal structure of human D-dopachrome tautomerase, a homologue of macrophage migration inhibitory factor, at 1.54 A resolution. Biochemistry 38, 3268-3279.

Sun, H. W., Bernhagen, J., Bucala, R., and Lolis, E. (1996a). Crystal structure at 2.6-A resolution of human macrophage migration inhibitory factor. Proc. Natl. Acad. Sci. U.S.A. 93, 5191-5196

Sun, H. W., Swope, M., Cinquina, C., Bedarkar, S., Bernhagen, J., Bucala, R., et al. (1996b). The subunit structure of human macrophage migration inhibitory factor: evidence for a trimer. Protein Eng. 9, 631-635.

Sun, J., Hartvigsen, K., Chou, M. Y., Zhang, Y., Sukhova, G. K., Zhang, J., et al. (2010). Deficiency of antigen-presenting cell invariant chain reduces atherosclerosis in mice. Circulation 122, 808-820.

Sunderkotter, C., Nikolic, T., Dillon, M. J., Van Rooijen, N., Stehling, M., Drevets, D. A., et al. (2004). Subpopulations of mouse blood monocytes differ in maturation stage and inflammatory response. J. Immunol. $172,4410-4417$.

Suzuki, J., Jin, Z. G., Meoli, D. F. Matoba, T., and Berk, B. C. (2006). Cyclophilin A is secreted by a vesicular pathway in vascular smooth muscle cells. Circ. Res. 98, 811-817.

Swant, J. D., Rendon, B. E., Symons, M., and Mitchell, R. A. (2005). Rho GTPase-dependent signaling is required for macrophage migration inhibitory factor-mediated expression of cyclin D1. J. Biol. Chem. 280, 23066-23072.

Takahashi, K., Koga, K., Linge, H. M., Zhang, Y., Lin, X., Metz, C. N., et al. (2009). Macrophage CD74 contributes to MIF-induced pulmonary inflammation. Respir. Res. $10,33$.

Takahashi, K., Uwabe, Y., Sawasaki, Y., Kiguchi, T., Nakamura, H., Kashiwabara, K., et al. (1998). Increased secretion of urokinase-type plasminogen activator by human lung microvascular endothelial cells. Am. J. Physiol. 275, L47-54.

Tarnowski, M., Grymula, K., Liu, R., Tarnowska, J., Drukala, J., Ratajczak, J., et al. (2010). Macrophage migration inhibitory factor is secreted by rhabdomyosarcoma cells, modulates tumor metastasis 
by binding to CXCR4 and CXCR7 receptors and inhibits recruitment of cancer-associated fibroblasts. Mol. Cancer Res. 8, 1328-1343.

Tereshchenko, I. P., Petrkova, J., Mrazek, F., Lukl, J., Maksimov, V. N., Romaschenko, A. G., et al. (2009). The macrophage migration inhibitory factor (MIF) gene polymorphism in Czech and Russian patients with myocardial infarction. Clin. Chim. Acta 402, 199-202.

Thelen, M. (2001). Dancing to the tune of chemokines. Nat. Immunol. 2, 129-134.

Thelen, M., and Didichenko, S. A. (1997). G-protein coupled receptormediated activation of PI 3-kinase in neutrophils. Ann. N. Y. Acad. Sci. 832, 368-382.

Thelen, M., Munoz, L. M., RodriguezFrade, J. M., and Mellado, M. (2010). Chemokine receptor oligomerization: functional considerations. Curr. Opin. Pharmacol. 10, 38-43.

Thelen, M., and Thelen, S. (2008). CXCR7, CXCR4 and CXCL12: an eccentric trio? J. Neuroimmunol. 198, 9-13.

Tokuhira, M., Hosaka, S., Volin, M. V., Haines, G. K. III, Katschke, K. J. Jr., Kim, S., et al. (2000). Soluble vascular cell adhesion molecule 1 mediation of monocyte chemotaxis in rheumatoid arthritis. Arthritis Rheum. 43, 1122-1133.

Trettel, F., Di Bartolomeo, S., Lauro, C., Catalano, M., Ciotti, M. T., and Limatola, C. (2003). Ligandindependent CXCR2 dimerization. J. Biol. Chem. 278, 40980-40988.

van Zoelen, M. A., Yang, H., Florquin, S., Meijers, J. C., Akira, S., Arnold, B., et al. (2009). Role of toll-like receptors 2 and 4 , and the receptor for advanced glycation end products in high-mobility group box 1induced inflammation in vivo. Shock 31, 280-284.

Vera, P. L., Iczkowski, K. A., Wang, X., and Meyer-Siegler, K. L. (2008). Cyclophosphamide-induced cystitis increases bladder CXCR4 expression and CXCR4-macrophage migration inhibitory factor association. PLOS ONE 3:e3898. doi:10.1371/journal.pone.0003898

Verschuren, L., Kooistra, T., Bernhagen, J., Voshol, P. J., Ouwens, D. M., van Erk, M., et al. (2009). MIF deficiency reduces chronic inflammation in white adipose tissue and impairs the development of insulin resistance, glucose intolerance, and associated atherosclerotic disease. Circ. Res. 105, 99-107.

Verschuren, L., Lindeman, J. H., van Bockel, J. H., Abdul-Hussien, H., Kooistra, T., and Kleemann, R. (2005). Up-regulation and coexpression of MIF and matrix metalloproteinases in human abdominal aortic aneurysms. Antioxid. Redox Signal. 7, 1195-1202.

Wakasugi, K., and Schimmel, P. (1999). Two distinct cytokines released from a human aminoacyl-tRNA synthetase. Science 284, 147-151.

Wakasugi, K., Slike, B. M., Hood, J., Otani, A., Ewalt, K. L., Friedlander, M., et al. (2002). A human aminoacyl-tRNA synthetase as a regulator of angiogenesis. Proc. Natl. Acad. Sci. U.S.A. 99, 173-177.

Wantha, S., Alard, J. E., Megens, R. T., van der Does, A. M., Doring, Y., Drechsler, M., et al. (2013). Neutrophil-derived cathelicidin promotes adhesion of classical monocytes. Circ. Res. 112, 792-801.

Weber, C., Kraemer, S., Drechsler, M., Lue, H., Koenen, R. R., Kapurniotu, A., et al. (2008). Structural determinants of MIF functions in CXCR2-mediated inflammatory and atherogenic leukocyte recruitment. Proc. Natl. Acad. Sci. U.S.A. 105, 16278-16283.

Weber, C., and Noels, H. (2011). Atherosclerosis: current pathogenesis and therapeutic options. Nat. Med. 17, 1410-1422.

Weber, C., Schober, A., and Zernecke, A. (2004). Chemokines: key regulators of mononuclear cell recruitment in atherosclerotic vascular disease. Arterioscler. Thromb. Vasc. Biol. 24, 1997-2008.

Wennogle, L. P., Conder, L., Winter, C., Braunwalder, A., Vlattas, S., Kramer, R., et al. (1994). Stabilization of C5a receptor - G-protein interactions through ligand binding. J. Cell. Biochem. 55, 380-388.

Wilson, S., Wilkinson, G., and Milligan, G. (2005). The CXCR1 and CXCR2 receptors form constitutive homo- and heterodimers selectively and with equal apparent affinities. $J$. Biol. Chem. 280, 28663-28674.

Wu, B., Chien, E. Y., Mol, C. D., Fenalti, G., Liu, W., Katritch, V., et al. (2010). Structures of the CXCR4 chemokine GPCR with small-molecule and cyclic peptide antagonists. Science 330, 1066-1071.

Wu, Y., Wang, S., Farooq, S. M., Castelvetere, M. P., Hou, Y., Gao, J. L., et al. (2012). A chemokine receptor CXCR2 macromolecular complex regulates neutrophil functions in inflammatory diseases. J. Biol. Chem. 287, 5744-5755.

Wymann, D., Bluggel, M., Kalbacher, H., Blesken, T., Akdis, C. A., Meyer, H. E., et al. (1999). Human B cells secrete migration inhibition factor (MIF) and present a naturally processed MIF peptide on HLA-DRB1*0405 by a FXXL motif. Immunology 96, 1-9.

Xie, L., Qiao, X., Wu, Y., and Tang, J. (2011). Beta-arrestin1 mediates the endocytosis and functions of macrophage migration inhibitory factor. PLoS ONE 6:e16428. doi:10.1371/journal.pone.0016428

Xu, Q., Leiva, M. C., Fischkoff, S. A., Handschumacher, R. E., and Lyttle, C. R. (1992). Leukocyte chemotactic activity of cyclophilin. J. Biol. Chem. 267, 11968-11971.

Yang, D., Biragyn, A., Hoover, D. M., Lubkowski, J., and Oppenheim, J. J. (2004). Multiple roles of antimicrobial defensins, cathelicidins, and eosinophil-derived neurotoxin in host defense. Annu. Rev. Immunol. 22, 181-215.

Yang, D., Chen, Q., Yang, H., Tracey, K. J., Bustin, M., and Oppenheim, J. J. (2007). High mobility group box-1 protein induces the migration and activation of human dendritic cells and acts as an alarmin. J. Leukoc. Biol. 81, 59-66.

Yang, D., Chertov, O., Bykovskaia, S. N., Chen, Q., Buffo, M. J., Shogan, J., et al. (1999). Beta-defensins: linking innate and adaptive immunity through dendritic and T cell CCR6. Science 286, 525-528.

Yang, D., Chertov, O., and Oppenheim, J. J. (2001). Participation of mammalian defensins and cathelicidins in anti-microbial immunity: receptors and activities of human defensins and cathelicidin (LL-37). J. Leukoc. Biol. 69, 691-697.

Yang, X. L., Skene, R. J., McRee, D. E., and Schimmel, P. (2002). Crystal structure of a human aminoacyl-tRNA synthetase cytokine. Proc. Natl. Acad. Sci. U.S.A. 99, 15369-15374.

Yende, S., Angus, D. C., Kong, L., Kellum, J. A., Weissfeld, L., Ferrell, R., et al. (2009). The influence of macrophage migration inhibitory factor gene polymorphisms on outcome from communityacquired pneumonia. $F A S E B J$ 23, 2403-2411.
Yurchenko, V., Zybarth, G., O'Connor, M., Dai, W. W., Franchin, G., Hao, T., et al. (2002). Active site residues of cyclophilin A are crucial for its signaling activity via CD147. J. Biol. Chem. 277, 22959-22965.

Zabel, B. A., Wang, Y., Lewen, S., Berahovich, R. D., Penfold, M. E., Zhang, P., et al. (2009). Elucidation of CXCR7-mediated signaling events and inhibition of CXCR4-mediated tumor cell transendothelial migration by CXCR7 ligands. J. Immunol. 183, 3204-3211.

Zernecke, A., Bernhagen, J., and Weber, C. (2008). Macrophage migration inhibitory factor in cardiovascular disease. Circulation 117, 1594-1602.

Zhang, B., Shen, M., Xu, M., Liu, L. L., Luo, Y., Xu, D. Q., et al. (2012). Role of macrophage migration inhibitory factor in the proliferation of smooth muscle cell in pulmonary hypertension. Mediators Inflamm. 2012, 840737.

Zhang, Y., and Wang, H. (2012). Integrin signalling and function in immune cells. Immunology 135, 268-275.

Zou, Y. R., Kottmann, A. H., Kuroda, M., Taniuchi, I., and Littman, D. R. (1998). Function of the chemokine receptor CXCR4 in haematopoiesis and in cerebellar development. Nature 393, 595-599.

Conflict of Interest Statement: The authors declare that the research was conducted in the absence of any commercial or financial relationships that could be construed as a potential conflict of interest.

Received: 20 March 2013; paper pending published: 04 April 2013; accepted: 29 April 2013; published online: 16 May 2013.

Citation: Tillmann S, Bernhagen J and Noels H (2013) Arrest functions of the MIF ligand/receptor axes in atherogenesis. Front. Immunol. 4:115. doi: 10.3389/fimmu.2013.00115

This article was submitted to Frontiers in Chemoattractants, a specialty of Frontiers in Immunology.

Copyright (C) 2013 Tillmann, Bernhagen and Noels. This is an open-access article distributed under the terms of the Creative Commons Attribution License, which permits use, distribution and reproduction in other forums, provided the original authors and source are credited and subject to any copyright notices concerning any third-party graphics etc. 